OPEN ACCESS

Edited by:

Kenth Gustafsson,

University College London,

United Kingdom

Reviewed by:

Francesco Nicoli,

University of Ferrara, Italy

Katalin A. Wilkinson,

Francis Crick Institute,

United Kingdom

*Correspondence:

David J. Dowling

david.dowling@childrens.harvard.edu

${ }^{t}$ These authors have contributed equally to this work

Specialty section:

This article was submitted to

T Cell Biology,

a section of the journal

Frontiers in Immunology

Received: 31 January 2021 Accepted: 21 December 2021 Published: 10 February 2022

Citation:

Barman S, Soni D, Brook B, Nanishi E and Dowling DJ (2022)

Precision Vaccine Development:

Cues From Natural Immunity.

Front. Immunol. 12:662218. doi: 10.3389/fimmu.2021.662218

\section{Precision Vaccine Development: Cues From Natural Immunity}

\author{
Soumik Barman ${ }^{1,2}$, Dheeraj Soni ${ }^{1,2 t}$, Byron Brook ${ }^{1,2 \dagger}$, Etsuro Nanishi ${ }^{1,2}$ \\ and David J. Dowling ${ }^{1,2 *}$ \\ 1 Precision Vaccines Program, Division of Infectious Diseases, Boston Children's Hospital, Boston, MA, United States, \\ 2 Department of Pediatrics, Harvard Medical School, Boston, MA, United States
}

Traditional vaccine development against infectious diseases has been guided by the overarching aim to generate efficacious vaccines normally indicated by an antibody and/or cellular response that correlates with protection. However, this approach has been shown to be only a partially effective measure, since vaccine- and pathogen-specific immunity may not perfectly overlap. Thus, some vaccine development strategies, normally focused on targeted generation of both antigen specific antibody and T cell responses, resulting in a long-lived heterogenous and stable pool of memory lymphocytes, may benefit from better mimicking the immune response of a natural infection. However, challenges to achieving this goal remain unattended, due to gaps in our understanding of human immunity and full elucidation of infectious pathogenesis. In this review, we describe recent advances in the development of effective vaccines, focusing on how understanding the differences in the immunizing and non-immunizing immune responses to natural infections and corresponding shifts in immune ontogeny are crucial to inform the next generation of infectious disease vaccines.

Keywords: antigens, natural infection, innate immunity, adaptive immunity, immune system, vaccines, vitaPAMP, adjuvants

\section{INTRODUCTION}

Apart from clean drinking water and sanitation, vaccination is one of the most effective medical interventions to avert infectious diseases $(1,2)$. Despite the great successes of past revolutions in vaccinology, current vaccine technologies may still provide suboptimal protection in vulnerable populations, such as infants (1) and the elderly (3). This is an important unmet need for these vulnerable age-groups, but there are important lessons that can be taken from the breadth of vaccinology work performed for future vaccine design. Moreover, there is a growing need to develop improved vaccine strategies for globally emerging respiratory infections such as tuberculosis, pertussis, influenza and coronaviruses including the pertinent severe acute respiratory syndrome coronavirus 2 (SARS-CoV-2), the causative agent of the severe coronavirus disease 2019 (COVID-19) pandemic.

Historically, the earliest efficacious vaccine was constructed by using live attenuated pathogen small pox to induce protective immunity (4). Subsequently, inactivated, live attenuated, subunit, 
recombinant, polysaccharide and conjugate vaccines-which all induce humoral and cell mediated immunity-have been used to protect against different viral and bacterial infections. The classical purpose of vaccination is to establish a long-lived state of immunological memory to a given pathogen which can mediate an accelerated response to that pathogen upon secondary infection (5). Vaccines of variable effectiveness against several diseases, including pertussis, influenza and tuberculosis, have been available for many years. In the last few decades, a lack of vaccine induced immunity in distinct populations, especially newborns and older adults, have been reported with impairments attributed to an absence of functional adaptive immunity (6), alternative microbe pathogenicity/ activity in newborns/aged compared to adults, and alternative immune regulation processes (7).

Subunit or inactivated vaccines have proven effective against most childhood infections, like tetanus, diphtheria, pertussis, flu and meningitidis (8). The early life window of vulnerability alongside abnormally quick waning immunity from early life vaccinations, elicits major concerns in modern vaccinology (9). A major contributing factor could be the ontological differences in the immune responses. Firstly, upon pathogen challenge or vaccination, the inability of the neonatal and infant immune system to mount a polyfunctional $\mathrm{T}$ helper (Th) polarizing response (10), shifting away from protective Th1 and cytotoxic $\mathrm{T}$ cell immunity toward dysregulated Th2 and Th17 polarization (11). Secondly, during an infection microbial antigens act as distinct pathogen associated molecular patterns (PAMPs) and viability-associated PAMPs (vita-PAMPs) which elicit broad and long-lasting immune responses. Live vaccines (containing weakened or attenuated form of the microbe) have been able to mimic these responses more closely. Interestingly, growing research suggests that adjuvants and delivery systems may lead to long term immunity by simulating immune responses similar to exposure to live microorganisms $(2,12,13)$. Here, we discuss three examples, tuberculosis, pertussis and influenza, in which lessons can be learnt from our current understanding of natural pathogen-specific immunity which can better guide (Box 1) novel vaccination strategies to elicit targeted and effective immune activation in neonates and infants, with possible applicability in vulnerable elders and those with immunocompromised status.

BoX 1 | Key Considerations for the Study of Natural and Unnatural Immunity to Inform Precision Vaccinology

Improved understanding of tuberculosis, pertussis and influenza antigen structure, natural immunity and immunopathology may advance the design of novel vaccine candidates. Natural immunity achieved by environmental exposure of microorganisms is responsible for immunological imprinting in humans (14). Yet a number of important caveats need to be addressed, including: i) whether induction of beneficial unnatural immunity can be incorporated into the designing of broad spectrum next generation vaccines [reviewed in $(15,16)]$, ii) whether these strategies can specifically induce innate immunity and vaccine efficacy in early and later life [reviewed in $(6,11)$ and (17)], and iii) how can a growing body of vaccine adjuvants, in combination with formulation science of vaccine delivery, such as lipo-nanoparticle based mRNA technologies (3), be used to open up a new toolbox for vaccinologists [reviewed in (12) and (13)].

\section{Mycobacterium tuberculosis AND BACILLE CALMETTE GUERIN}

Tuberculosis (TB) is a leading bacterial cause of mortality worldwide and is caused by an infectious agent named Mycobacterium tuberculosis (MTB) (18). Bacille Calmette-Guérin (BCG), the live attenuated Mycobacterium bovis vaccine, is the only licensed vaccine for $\mathrm{TB}$ to date. It provides protection against disseminated childhood TB but BCG efficacy wanes slowly over time (10-15 years post-vaccination) (19). BCG vaccination has little effect against adult pulmonary $\mathrm{TB}$ infection which is the most communicable form of $\mathrm{TB}(20)$ and it comparatively carries a greater impact with higher death rates in those over 65 years of age (21). The emergence of drug-resistant strains (22) and limited understanding of protective immunity against MTB has become a major caveat in developing a novel effective TB vaccine.

\subsection{Innate Immunity to MTB}

Emergence of innate immunity is essential between MTB and host which eventually initiate the long term memory responses. Lung resident macrophages, neutrophils, dendritic cells (DCs), and natural killer (NK) cells are the major participants of pulmonary innate immunity. As an intracellular pathogen, MTB first comes in contact with airway epithelial cells and is phagocytosed by lung-resident macrophages (23). During the innate response, phagocytosed MTB can be cleared from the phagosome or induce Th1 type adaptive immunity (Figure 1A) via antigen processing and presentation (24). After infection, pattern recognition receptors (PRRs) of macrophages recognize pathogen-associated molecular patterns (PAMPs) of MTB. PRRs including Toll-like receptors (TLRs), Nod-like receptors (NLRs) and C-type lectin receptors (CLRs) coordinate multiple signaling cascades (25). TLRs recognize mycobacterial glycolipids, lipoproteins, carbohydrates or nucleic acids as a PAMP. Signaling between MTB's PAMPs and TLRs activates MyD88 and elicits proinflammatory cytokines or type I IFNs (25). All TLRs use MyD88 for their downstream signaling except TLR3 (26). Involvement of TLR2, TLR4, TLR8 and TLR9 are well documented during MTB infection $(27,28)$. TLR2, TLR4, TLR7, TLR8 and TLR9 polymorphisms in human are associated with greater exposure to pulmonary MTB infection $(25,28)$.

After recognition, MTB is eliminated by several pathways including phagocytosis, inflammasome activation, autophagy and apoptosis (29). After infection, macrophages differentiate into either classically activated macrophage inflammatory type 1 ' $\mathrm{M1}$ ' or alternatively activated 'M2' macrophages (25). 'M1' macrophages are pro-inflammatory and anti-microbial in nature while ' $\mathrm{M} 2$ ' macrophages are anti-inflammatory in nature $(30,31)$ and poor antigen presenting cells (25). Recent research highlights the M1/M2 model after MTB infection (30) though the exact mechanism remains a dilemma (31). MTB DNA is sensed by cGAS-STING pathway and triggers downstream cytokine production and autophagy $(32,33)$. STING pathway is found to be important for DC activation but unessential for protective immunity (34). DCSIGN (CD209) acts as an entry point of MTB to DCs (35). CD14 $\mathrm{HLA} \mathrm{DR}^{+} \mathrm{DC}-\mathrm{SIGN}^{+}$cells are probably responsible for endocytosis 


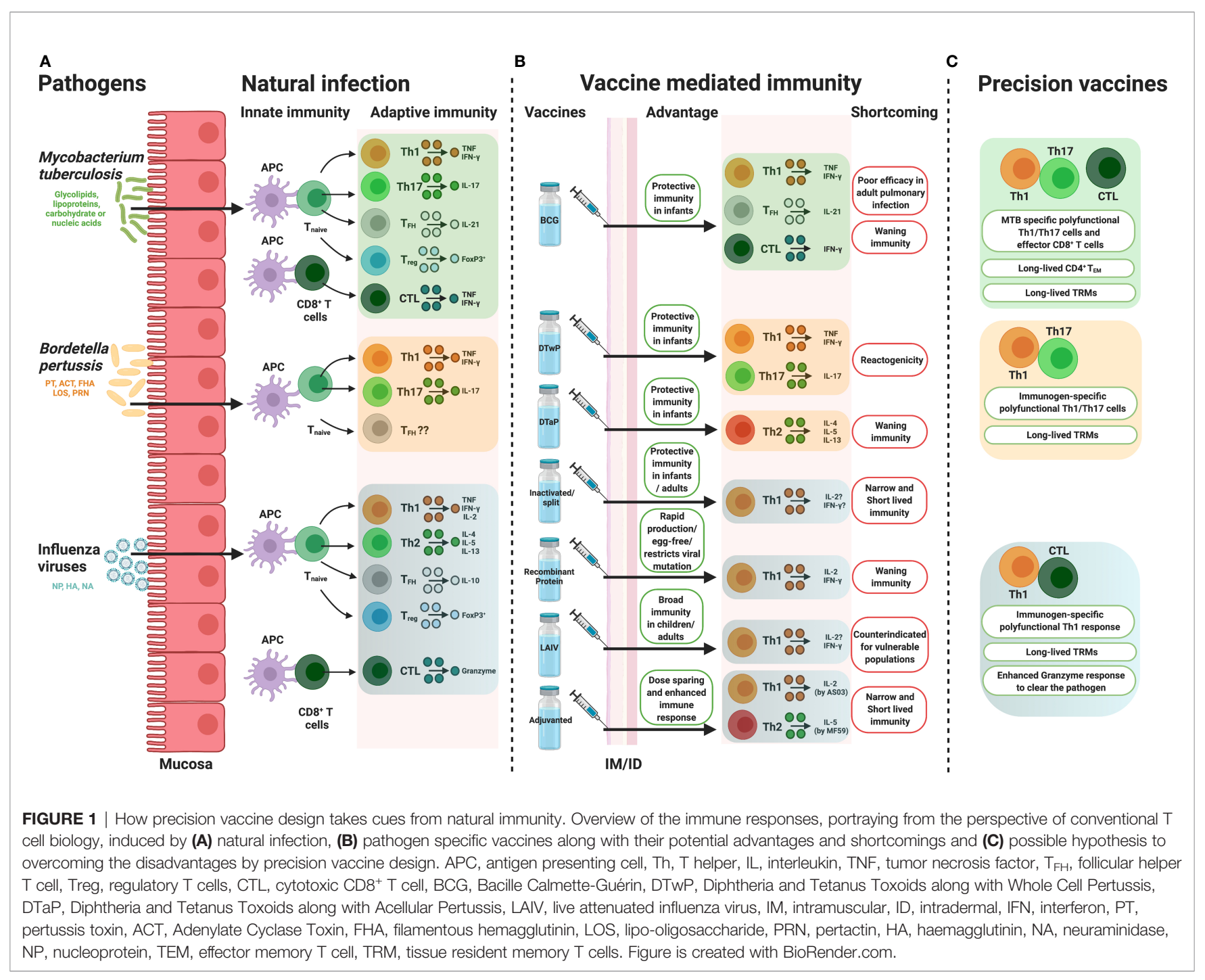

of MTB in humans (36). Major histocompatibility complex (MHC) unrestricted innate lymphoid cells (ILCs), which are enriched in intestinal and alveolar mucosal surface, also play a crucial role in human MTB infection (37). In active TB patients circulatory ILCs in blood were found to be depleted and restored upon treatment. In general, ILCs can module both innate and adaptive immune responses by producing interferon (IFN) $\gamma$ (by type 1 ILCs), interleukin (IL)-4, IL-5, IL-13 (by type 2 ILCs), IL-17 and IL-22 (by type 3 ILCs) (37). There is evidence that CD117 ${ }^{+}$ILC3 specifically contribute in the immune response to $\operatorname{MTB}(37,38)$. Neutrophils, granulocytes and mast cells have protective roles against MTB (35). Little is known about the exact immune mechanism of neutrophils and mast cells in human MTB infection $(25,35)$ which might open avenues for further research.

\subsection{Adaptive Immunity Achieved by Natural MTB Infection}

For immunologists to develop a new and more effective vaccine against $\mathrm{TB}$, relevant immunological outputs must be considered to select the optimum formulation, delivery mechanisms and adjuvantation. Prioritization of readouts (e.g., antibody titer, antigen-specific Th1 polarization, $\mathrm{T}$ cell polyfunctional activity etc.) will need to either be instructed by correlating and implicating functions following novel vaccine development or by further understanding of the most important immunological outputs following natural MTB infection. T cells have a central role in protective and adaptive immunity and they are the prime candidates to target and trigger effective adaptive immunity. Predominantly, activated antigen presenting cells (APCs) induce proliferation of antigen specific naive $\mathrm{CD} 4^{+} \mathrm{T}$ cells (Figure 1A). The mechanism of antigen delivery in humans after MTB infection remains somewhat obscure. Peripheral blood $\mathrm{CD}_{1}{ }^{+}$ cells have been reported to initiate T helper 1 (Th1) polarization in active MTB patients $(39,40)$. Impairing IFN $\gamma$ production by

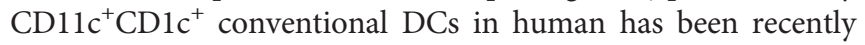
characterized (41). In the last 10 years, T cell expansion/ contraction kinetics and development of memory signature by $\mathrm{T}$ cells have been well established by the studies of $\mathrm{CD} 8^{+} \mathrm{T}$ cell 
responses against acute viral infection (42-44). These cannot, however, be directly translated to bacterial infection and MTB disease. Working with slow growing pathogens like MTB and lack of tetramers to target antigen specific T cells $(42,45)$ along with unavailability of transgenic $\mathrm{T}$ cell receptor mice are the intricate barriers for $\mathrm{T}$ cell readouts. High sensitivity multi-color flow cytometric assay and cytometry by time-of-flight (CyTOF) might shed light on the unexplored phenotype of APCs during MTB infection and are identified here to be essential areas of future research.

Comparative studies with MTB infected individuals demonstrated accumulation of MTB specific $\mathrm{TNF}^{+} \mathrm{CD}^{+}$(46) and polyfunctional (IFN $\gamma$, IL-2, and TNF producing) T cells (47, 48). Th1 polarization and IFN $\gamma$ or TNF production are essential to clear MTB infection $(29,49)$. IFN $\gamma$ heightened antimycobacterial defense in macrophages, whereas TNF synergizes with IFN $\gamma$ to combat against MTB infection (30). A balanced immune response is required, as IFN $\gamma$ production by $\mathrm{T}$ cells has also been implicated to be associated with TB in a potentially age-dependent manner (50). It remains to be determined whether this was a causative or associated observation. However, other $\mathrm{CD}^{+} \mathrm{T}$ cell subsets, especially IL-17 (Th17) and FoxP $3^{+}$regulatory $\mathrm{CD}^{+}{ }^{+} \mathrm{T}$ cells also contribute to the host resistance against MTB infection $(33,51,52)$ (Figure 1A). MHC-I-restricted $\mathrm{CD}^{+} \mathrm{T}$ cells contribute to defense against MTB infection $(47,53)$. Synergy between $\mathrm{CD} 8^{+}$and $\mathrm{CD} 4^{+}$ T cells restricts intracellular MTB growth $(54)$. NK cells $(55,56)$ and $\mathrm{B}$ cell responses to MTB infection have also been characterized in the clinical spectrum (38). B cell responses to tuberculosis have had conflicting and potentially negative results in response to infection/disease. Animal models have identified either no effect or delayed pathogenesis from MTB following B cell depletion (57), but animal models can have differential responses compared to human pathology (58), limiting the cross-species conclusions that can be drawn. B cells and antibodies have been functionally implicated in anti-TB immunity. B cells have been observed to accumulate around MTB granulomas in the lungs, induce various cytokines like IL-10 (57), form germinal center-like structures in non-secondary lymphoid tissues that support cell proliferation and restrict TB dissemination and instruct effective $\mathrm{T}$ cell responses $(57,59)$. Further B cell importance in containing TB disease can be observed in the importance of humoral immunity. Individuals repeatedly exposed but uninfected, termed "resisters" (60), have had a significant induction of TB-specific IgG levels and antibodies specific to ESAT-6 and CFP-10 in latent TB can separate from subjects with active TB (59). TB-specific IgA secretion into the lungs has been implicated following infection which could contribute to antibody-dependent cellular phagocytosis and cytotoxicity, activation of complement, direct TB neutralization, stimulation of cell mediated immunity and intracellular identification through tripartite motif containing protein 21 (TRIM21) [as reviewed in (59)]. Donor Unrestricted $\mathrm{T}$ cells (DURT) or unconventional T cells, i.e. mucosal-associated invariant T (MAIT) cells, CD1-restricted T cells and $\gamma \delta$ T cells play a crucial part in early stage of defense $(61,62)$ by recognizing nonpeptide mycobacterial antigens (33). Tissue resident memory $\mathrm{T}$ cells (TRM) proximally located in non-lymphoid lung tissue can protect from $\mathrm{TB}$ in various models, independently from Th1 polarization, representing another immune mechanism of interest for protection $(63,64)$. TRM could also contribute to greater inflammatory damage and additional research is required to understand the involved mechanisms (63). Activated and exhausted TRMs were found to be predominant at infection sites in TB patients (65). A very recent study identified the protective role of IL-17 producing TRM cell clusters in MTB infected human lungs (66). Further in vivo observations and correlates of protection to identify which immunological response(s) are essential are needed before development of new vaccines against MTB.

\subsection{Protective Immunity After BCG Immunization}

At present, BCG is the only $\mathrm{WHO}$ recommended tuberculosis vaccine indicated for human use in endemic areas. BCG offers infants protective immunity against disseminated tuberculosis (67). Unfortunately, BCG is less efficacious against adult pulmonary MTB infection $(68,69)$. Some possible hypotheses for the poor efficacy in older persons could be due to the improper induction of memory precursor effectors cells (MPECs) which are capable of generating long-lived memory cells $(53,69)$. Reinfection could also be a hindrance to BCG efficacy $(69,70)$. Age-dependent innate immunological responses to BCG have also been identified in a neonatal and adult mouse model (71). Lastly and importantly, BCG strain variants and the degree of viability between MTB strains is now recognized to drive distinct immunological outcomes after BCG vaccination $(72,73)$, highlighting the importance of the immune system's ability to recognize viability to elicit strong innate immune responses against vita-PAMPs (74) and should be induced through adjuvantation. This is particularly evident in the as of yet most efficacious new development of a subunit TB vaccine, $\mathrm{M} 72 / \mathrm{AS}_{\mathrm{E}}$ with $\mathrm{AS} 01_{\mathrm{E}}$ adjuvantation (75) to induce TLR4 signaling (76) that is otherwise triggered by the vita-PAMPs (77). The $54 \%$ efficacy of $\mathrm{M} 72 / \mathrm{AS} 01_{\mathrm{E}}$ was significant for an inactive nonreplicating vaccine (75), particularly compared to the range of $0-80 \%$ efficacy for BCG (78), but still highlights an unmet requirement for further vaccine development. Pursuing the development of a new vaccine will not necessarily replace the need for BCG vaccination. Human trials have displayed potential efficacy of a heterologous prime boost with neonatal BCG vaccination followed by adolescent immunization with an alternative protein subunit, H4:IC31, that reduced signatures of long-term infection (79). Understanding the variable responses to vaccination already present in humans is crucial to identify how to design novel and superior vaccines.

As a "self-adjuvanted" vaccine, BCG triggers innate immunity through TLR2, TLR4, TLR8, C-type lectins and Mincle $(73,80)$ after intradermal vaccination. When co-delivered, BCG can therefore act to enhance the immunogenicity of non-related protein vaccines (81). After internalization by APCs, BCG induces DC maturation (82) and migration followed by antigen 85 mediated production of TNF, IL-1 $\beta$ and IL- 6 which promote immune cell activation $(80,83)$. BCG develops adaptive 
immunity when antigens are processed by MHC class II and I pathways and activated both $\mathrm{CD} 4^{+}$and $\mathrm{CD} 8^{+} \mathrm{T}$-cell subsets with elevated production of $\operatorname{IFN} \gamma(73,83)$ (Figure 1). BCG stimulates the generation of effector memory $\mathrm{T}\left(\mathrm{T}_{\mathrm{EM}}\right)$ cells which has been phenotyped as CD44 ${ }^{\text {high }} \mathrm{CD}^{\text {low }} \operatorname{CCR}^{\text {low }}(84,85) . \mathrm{T}_{\mathrm{EM}}$ cells usually engaged in various cytokine production and affected tissue specific homing (86). Induction of humoral responses has been documented 4-8 weeks post vaccination period ( 80 , 87). B cell response triggers the induction of IgG (88) and longlived memory B cells (89). Induction of TRMs following BCG immunization depends on the route of immunization (90). MTB specific TRM responses are shown to be induced by mucosal BCG immunization $(90,91)$ rather than intradermal (91) or subcutaneous BCG administration (90). MTB specific TRMs were proven to participate in a protective role upon pulmonary reinfection (92). TLR8 on human monocyte senses live BCG and promotes $\mathrm{T}$ follicular helper $\left(\mathrm{T}_{\mathrm{FH}}\right)$ cell differentiation (74) and might be a key player in BCG specific humoral responses. Identification of the PRR-mediated immune activation profiles by different strains of BCG could reveal important correlations to various levels of protection and identification of beneficial targets (i.e., antigens, TLRs) for future vaccine development efforts.

\subsection{Lessons From Natural MTB Infection and Future Vaccine Strategies}

Deep understanding of the BCG mediated immune protection, MTB pathogenesis and human immunogenicity are still unclear. TB infection can be categorized into different stages with transmission, development of active disease and continuation to latent TB infection (LTBI) (93). Interestingly, an estimated 9/ 10 individuals who develop TB-specific $\mathrm{T}$ cell responses fail to develop active disease (93), suggesting that there could be immunological mechanisms triggered by TB that may be sufficient to protect from active infection in some individuals (53). This is not sufficient protection, however, as the remaining $1 / 10$ TB-exposed individuals progress to active disease and afterwards, in survivors, progress to LTBI with a lifelong danger of TB reactivation $(53,93)$. The disease stages are often presented as either active or latent but can be further observed as a disease spectrum (93). Furthermore, a group of exposed individuals, termed "resistors", have remained uninfected (by tuberculin skin test or IFN $\gamma$ release assay (IGRA) negative) despite high TB exposure, suggesting some individual's ability to trigger effective natural immunity $(53,60)$. Resistors were characterized by IgM, class-switched IgG antibody responses, high accumulation of IL-2 $(94,95)$ and IFN $\gamma$ independent T cell responses to the TB specific antigens (60), identifying important mechanisms to induce post-vaccination. This may not however be the entire immune profile required to contain infection, as TB reactivation in HIV individuals has been observed prior to a depletion of $\mathrm{CD}^{+} \mathrm{T}$ cells (93). Further studies investigating human TB infection are needed to evaluate which combination of immune mechanisms allow resistors to avoid active infection to identify the essential pathways needed to be induced in a wider population. Meanwhile, adjuvanted multi-antigen TB vaccine development can target induction of multi-antigen and multi- faceted immune responses, triggering IgM, IgG, lung resident TRMs and IFN $\gamma$ independent immune responses with the goal of overcoming TB's active impairment of host immunity that otherwise restricts immunity and prevents sterilizing immunity.

A single highly immunogenic antigen that can induce sterilizing protective immunity against all disease stages of TB in a varied population has not yet been discovered and may not be possible. Selection of which vaccine antigen to induce protection from can be guided by observing natural immune responses to $\mathrm{MTB}$, through focusing on pathways that can convey partial immunity. MTB encodes a wide variety of proteins with 4,019 open reading frames, one fourth of which are hypothetically expressed proteins that need to be experimentally verified $(96,97)$. MTB has evolved to actively produce factors inhibiting innate immune responses (98), identifying previous selective pressures that protected from infection. Identifying natural protection from disease can highlight effective vaccination targets. This highlights the need to target multiple antigens, potentially from multiple disease stages, so that effective immunity is induced prior to infection that spans the breadth of TB disease. The approach of selecting immunodominant antigen targets to vaccinate against is not always effective though (99) and targeted induction of protective immune responses may be required to maximize protection.

Numerous efforts have been attempted to replace the centuryold BCG vaccine. Various candidates have made it to clinical trials, with some efficacy observed in completed trials and others ongoing as of 2021. These vaccines fall into various vaccination categories, including adjuvanted antigen (M72:AS01 $\mathrm{E}, \mathrm{H} 56: \mathrm{IC} 31$, ID93:GLA-SE and GamTBvac), viral vectors with TB antigens (TB/FLU-04L, MVA85A and Ad5Ag85A), inactivated vaccines (M. vaccae, $M$. indicus pranii, DAR-901 and RUTI) and liveattenuated (VPM1002, BCG revaccination and MTBVAC) (53, $100,101)$. M72:AS01 $\mathrm{E}$ particularly had similar efficacy to BCG's $50 \%$ reduction in IGRA conversion, with a $50 \%$ reduction in disease (75). This level of protection was however insufficient at overcoming BCG's protective effect and indicates an unmet need for TB prevention. Ongoing vaccine development includes evaluation of various adjuvants and alternative antigen and adjuvant delivery technologies (102). The recent development of mRNA encapsulated in lipid nanoparticles to protect from SARS-CoV-2 has garnered an interest in evaluating the technologies' potential in TB prevention (103). Modern vaccinology solutions are being evaluated to garner greater protection from TB than the century-old BCG, but significant efforts are still needed.

\section{Bordetella pertussis}

Pertussis or whooping cough caused by highly contagious Bordetella pertussis (BP) is a major health concern in the infant population. Pertussis was the largest cause of infant morbidity and mortality during the first few decades of the $20^{\text {th }}$ century (104). Despite the routine immunization with whole cell pertussis $(\mathrm{wP})$ and acellular pertussis $(\mathrm{aP})$ vaccine, pertussis 
remains resurgent. Lower efficacy of aP comparative to reactogenic ${ }_{\mathrm{wP}}$ and waning of protective immunity after aP immunization might be an effect of increasing pertussis incidence in developed countries. Reviewing and highlighting natural immunity as well as differences in immunological stimulation by aP and ${ }_{\mathrm{wP}}$ could identify the significant pathways needed for long term protection.

\subsection{Innate/Adaptive Immunity to Pertussis}

$\mathrm{BP}$ uses wide variety of virulence factors as a PAMPs involving Pertussis Toxin (PT), Adenylate Cyclase Toxin (ACT), Filamentous hemagglutinin (FHA), Pertactin (PRN) and Lipooligosaccharide (LOS). FHA helps BP in adherence to respiratory mucosa and ACT helps in invasion while PT detours the phagocytosis of BP by APCs (105). After colonization to respiratory epithelium, BP initiates the arm of innate immune responses which later helps to shape the adaptive arm. Different classes of PRRs of macrophages including TLRs, NLRs and CLRs recognize PAMPs of BP (106), therefore, with biomimicry, adjuvantation inducing similar pathways may improve efficacy. Clinical isolates of BP generally enhance TLR2 and TLR4 signaling (107). PT and LOS activate TLR2 and 4 signaling in human $(106,108)$, trigger IL-12 production (109) while FHA acts as a TLR2 ligand (110) and interacts with ACT (111) to play a crucial role in natural immunity. Destruction of phagocytosed BP by macrophage activated IFN $\gamma$ and IL-17 is debatable (105). The specific role of PRN in human BP pathogenesis remains unclear though it helps to overcome neutrophil-mediated clearance in mice (112). Targeting any, or multiple, of these BP-produced proteins could be valid immunological targets.

After BP infection, professional APCs prime the differentiation and proliferation of naïve $\mathrm{T}$ cells into effector and memory $\mathrm{T}$ cells. While the roles of $\mathrm{CD} 4^{+} \mathrm{T}$ cells in BP infection are well documented (Figure 1), the specific role of $\mathrm{CD}^{+} \mathrm{T}$ cells is less clear (113). Generally, naïve T cells differentiate into TNF and IFN $\gamma$ producing Th1 (114, 115), and IL-17 producing Th17 cells after natural BP infection (116). Th1 and Th17 cell mediated immune responses in bacterial clearance and protection are demonstrated in mice and baboon infection models (116). Animal study revealed that tissue resident memory (TRM) $\mathrm{T}$ cells (phenotypically defined as $\left.\mathrm{CD} 4^{+} \mathrm{CD} 69^{+}\right)$confer long term protection against BP $(117,118)$. The role of TRM in human BP infection remains unexplored (119). Macrophage dependent IFN $\gamma$ producing $\mathrm{CD}^{+} 6^{+} \mathrm{NK}$ cells activation in human is reported very recently (120). IL-17 dependent neutrophil recruitment (121) and existence of Foxp3+ Treg cells in lungs of BP infected mice (108) were documented. BP specific IgG and IgA might have a role in clearance of bacterial load by neutralizing BP toxin or by opsonization (122). Further studies are necessary to dissect the protective role of such cells in human BP infection, so that important correlates of protection can be identified post-vaccination.

\subsection{Whole Cell and Acellular Vaccine- Induced Immunity}

Emergence of BP infection in the US population was dramatically reduced $(99 \%)$ by the introduction of alum containing wP vaccine in 1950 s $(123,124)$. In the USA during mid 1990s, alum-formulated aP replaced wP based formulations. The main driving factor was the desire to further reduce the rare incidents of febrile seizures in infants post vaccination, while nearly always recoverable, were associated with wP induced local and systemic reactogenicity $(124,125)$. The formulation of alum adjuvanted Diphtheria and Tetanus Toxoids along with Acellular Pertussis (DTaP) vaccine is variable, ranging from a mixture of virulence factors like $\mathrm{PT}$ alone or with FHA, PRN and/or fimbriae serotypes (FIM 2/3) (112, 126, 127). Despite successful DTaP vaccination, resurgence of pertussis was observed in developed countries in the first decade of $21^{\text {st }}$ century (128). Lower efficacy and waning immunity in response to DTaP has become a major concern (129).

Formulation of alum adjuvanted Diphtheria and Tetanus Toxoids along with Whole Cell Pertussis (DTwP) vaccine acts differently and induces distinct immunity profile in humans than DTaP. DTwP which is derived from killed BP, is enriched with several prominent antigens (130) along with exogenous TLRs agonists. wP primed $\mathrm{BP}$ specific $\mathrm{CD}^{+} \mathrm{T}$ cell immunity is Th1/ Th17 biased which mimics cellular immunity profile after natural infection $(128,131)$ (Figure 1). The protective role of BP specific IFN $\gamma$ producing $\mathrm{CD}^{+} \mathrm{T}$ cells (Th1 cells) and IL-17 producing CD4 ${ }^{+} \mathrm{T}$ cells (Th17 cells) have been well demonstrated in animal models (119). In mice, BP infection usually induces IgG2a/2b antibodies which triggers cell mediated and IgG induced humoral responses (132). All IgG subclasses (IgG1/2a/2b and 3) were induced by $\mathrm{wP}$ immunization, which clearly explains why $\mathrm{wP}$ immunization is linked to Th1/Th17 polarization (132). aP evokes IgG1 induction (132) and induces IL-4, IL-5 and IL-13 producing $\mathrm{CD}^{+} \mathrm{T}$ cells (Th2 cells) (Figure 1B) which does not confer protective immunity against nasal infection and transmission (119). wP induced respiratory TRM cells also participate in protective immunity in mice which were found to be absent followed by aP vaccination (118), but some evidence indicates that there may be a specialized role for Th17-polarzied TRM cell subsets in the control of nasal infection in $\mathrm{aP}$ immunized mice (133). Benchmarking $\mathrm{wP}$ versus aP immunization in human is challenging as in developed countries only aP vaccine is licensed. Interestingly, a recent study between $\mathrm{wP}$ and $\mathrm{aP}$ primed individuals showed that only wP prime evoked $\mathrm{BP}$ specific $\mathrm{CD} 4^{+} \mathrm{T}$ cells after aP boost (134). aP prime followed by aP boosted donors exhibited increased Th2 related cytokines, reduced IFN $\gamma$ and IL-17 production, defective $\mathrm{T}$ cell memory expansion and lower $\mathrm{T}$ cell proliferative capacity (134). Data from multiple cohort studies also proven that DTaP induces Th2 skewed immunity whereas DTwP primed Th1 biased immunity in human $(119,135,136)$. Moreover, aP vaccines do not inhibit colonization and transmission of the disease (137). Thereby, aP vaccines do not confer herd immunity in population (138). These outcomes partially elucidate the resurrection of pertussis in developed countries though further study is necessary to dissect the host immune response after BP pathogenesis and vaccination.

\subsection{Overcoming Waning Immunity and Lessons From Natural BP Infection}

Overall, the two main limitations of the current aP vaccine are its relatively short duration of effectiveness and the lack of local 
immunity in upper respiratory tract. Importantly, a study of infant olive baboon (Papio anubis) challenge model has revealed that convalescent animals are fully protective from subsequent bacterial challenge regarding upper-airway colonization, whereas aP vaccinated animals showed bacterial shedding (137). Thus, it is a reasonable approach to find cues to overcome these limitations in studies from natural infections and from more immunogenic wP vaccine. As summarized above, aP vaccineinduced immune responses can be distinguished from $\mathrm{wP}$ and natural infection-induced immune responses with its 1) weak Th1/Th17 polarizing $\mathrm{CD}^{+}{ }^{+} \mathrm{T}$ cell immunity, 2) low induction of tissue resident memory $\mathrm{T}$ cells and possibly 3 ) low functional antibody responses. Therefore, to hypothetically overcome the waning effectiveness of acellular vaccine, development and evaluation of a next generation $\mathrm{DTaP}$ vaccine is required which should prime Th1/Th17 polarization. Adjuvantation using TLR agonists or STING (stimulator of interferon genes) ligands might be a smart choice $(13,139,140)$. Alum adsorbed TLR7 agonist adjuvanted aP formulation primed BP specific Th1/Th17 polarization and humoral responses in adult mice than traditional aP formulation (141). Protection against BP aerosol exposure was achieved in TLR7 agonist adjuvanted aP formulation immunized mice group, similar to that triggered by wP (141). Preliminary study with a novel TLR7/8 agonist CRX727 (UM-3003) formulated DTaP (142), a collaborative work between University of Montana/Inimmune and Precision Vaccines Program/Boston Children's Hospital, revealed enhancement in early life immunogenicity and overcomes neonatal hyporesponsiveness to DTaP (143). Overcoming neonatal hyporesponsiveness is a major caveat in development of next generation acellular pertussis vaccine. Neonatal cells are Th2 biased due to hypomethylation in Th2 locus (122). Therefore, restoration of Th1 predominance could be achieved either by TLR7/8 adjuvantation or by live vaccine strain like BCG. TLR2 ligand from BP itself, is capable of driving innate immune responses along with protective homologous immunity upon respiratory challenge (144). Long lasting protection against nasal exposure in mice was reported by a novel adjuvant combination including STING and TLR-2 (145). aP formulated with STING and TLR-2 skewed Th1/Th17 polarization and triggers IL- $17^{+}$TRMs (145). TLR9 agonist adjuvanted DTaP confers enhanced protection than DTaP alone or TLR4 adjuvanted formulation in mice (146).

A promising live attenuated $\mathrm{BP}$ vaccine strain (BPZE1) is in human phase 2 trial $(127,147)$, and proven beneficial in mice and infant baboon models (148). Early protection in mice induced by BPZE1 is independent of the adaptive immune system but depends on TLR4 signaling pathway (149). GamLPV, another live intranasal BP vaccine strain, is also in phase $1 / 2$ trials (112). Using live BP strain as a vaccine, has certain advantages- i) a live strain has a variety of BP antigens compared to aP vaccines which only contain up to 5 antigens, ii) live attenuated strain mimics natural infection and provides sterilizing immunity. Improved vaccine efficacy should be achieved by live BP vaccine strain as TLR8 on innate immune cells senses live bacteria (74) and triggers $\mathrm{T}_{\mathrm{FH}}$ differentiation which is beneficial for inducing strong humoral immune responses (74). Lately, a first controlled human study with BP infection was conducted by a European collaboration to get the insight of microbiological and immunological features of $\mathrm{BP}$ pathogenesis $(150,151)$. This novel approach will allow us to dissect the mechanism of protection in the context of natural BP infection (151).

\section{INFLUENZA}

Influenza viruses belong to the Orthomyxoviridae family which represents enveloped viruses, with genome consisting of segmented negative-sense single-strand RNA segments (ssRNA). These ssRNA are tightly surrounded by nucleoprotein (NP), which along with glycoproteins such Haemagglutinin (HA) and neuraminidase (NA) are the viral components detected by antibodies, and also define the subtype of the virus (152). Although, there are 4 genera of this family namely A, B, C and $\mathrm{D}$; only influenza A and B are clinically relevant in humans and responsible for causing seasonal epidemics (known as the flu season) almost every winter across the world (153). Influenza infection in humans is initiated in the respiratory tract and in most cases is limited to this organ. Oral or nasal entry of the virus is initially countered by the mucus lining the respiratory epithelium. Upon successfully breaching the mucosal layer, the virus can attach and invade the respiratory epithelium where it can spread to both non-immune and immune cells [such as macrophages and dendritic cells (DCs)] in the respiratory tract $(152,154)$.

\subsection{Innate Immunity to Influenza}

Innate immune system forms a formidable barrier as part of the defense mechanism against influenza virus (152). Detection of the virus through the innate immune system occurs via at least three distinct classes of the PRRs; TLRs (including TLR3, TLR7 and TLR8), retinoic acid-inducible gene I (RIG-I) and the NODlike receptor family member NOD-, LRR- and pyrin domaincontaining 3 (NLRP3) (155). TLR3 detects virus-infected cells, and TLR7 (and TLR8 in humans) detect viral RNA endocytosed by the sentinel cells (i.e., cell-extrinsic recognition). However, RIG-I and NLRP3 are responsible for detection of virus present within the cytosol of infected cells (i.e., cell-intrinsic recognition). Lack of innate sensors and signaling pathways in mice challenged with high doses of influenza A virus has been demonstrated to result in mortality since the host succumbs to infection. However, with sub-lethal doses or inactive virus the host is able to survive the infection by mounting a protective adaptive immune response. Such studies have also expanded our understanding of the viral sensors that link innate recognition to adaptive immunity (152), which is an important progression in being able to model the disease in vivo and to test efficacy of vaccination and adjuvantation in a way that may mimic the natural pathways triggered by influenza infection.

Properly modelling influenza infection in vitro can be difficult. This is partly due to influenza virus-infected cells not generating 
dsRNA (156) due to the activity of cellular RNA helicase (157). Therefore, TLR3 likely recognizes unidentified RNA structures present in dying virus-infected cells that have been phagocytosed (158), changing the immunological signaling compared to in vivo observations. Activation of TLR3 in human respiratory epithelial cells (which constitutively express TLR3) is known to induce production of pro-inflammatory cytokines upon influenza virus infection but can also lead to pathology (159-161). Further, Tlr3 ${ }^{-/-}$ mice survive longer than their WT counterparts (despite higher viral loads in the lungs). However, viral challenge in $\mathrm{Tlr}^{-/-}$mice leads to reduced chemokine expression and infiltration of leukocytes and $\mathrm{CD}^{+} \mathrm{T}$ cells in the lungs (160). Surprisingly, with sub-lethal doses of influenza virus infection these mice are able to generate normal antibody responses as well as $\mathrm{CD} 4^{+} \mathrm{T}$ cell and $\mathrm{CD}^{+} \mathrm{T}$ cell responses, suggesting TLR3 is dispensable for generating $\mathrm{T}$ cell immunity (162). Thus, although TLR3 is crucial to curb viral replication, it simultaneously promotes the recruitment of innate and adaptive responses that result in damage to the host. Although TLR3 signaling can be damaging during host-mediated inflammation to disease, it may be beneficial to induce during vaccination to amplify protective immune responses.

In plasmacytoid dendritic cells (pDCs), independent of viral replication, TLR7 recognizes endocytosed ssRNA genomes within the influenza virion (152). Downstream of TLR7 signaling transcription factors are activated [either nuclear factor $-\kappa B(N F-\kappa B)$ or IFN-regulatory factor 7 (IRF7)] which promote expression of pro-inflammatory cytokines and type I IFNs, respectively. The role of TLR7, specifically in inbred mice, in innate defense remains unclear since contradictory studies have shown that TLR7 could be dispensable against high-dose influenza virus challenge. However, studies with sublethal doses of influenza virus have demonstrated pivotal role of TLR7 in eliciting robust antibody response, but not $\mathrm{T}$ cell responses. Thus, TLR7 expression is crucial for antiviral responses against influenza virus via recruitment of $\mathrm{B}$ cells to elicit antibody production. On the contrary, although TLR8 is expressed in human monocytes and macrophages, and its activation results in IL-12 but not IFN $\alpha$, however the exact role of TLR8 in influenza virus infection remains unclear.

\subsection{Adaptive Immunity to Influenza}

Although innate immunity is essential for restricting viral replication, the adaptive immune responses are critical for eventual viral clearance, recovery and protection from reinfection. This has been established by studies showing that influenza virus challenge in immunodeficient mice leads to significantly higher mortality than healthy controls $(163,164)$. Importantly, the HA and NA proteins are key targets of the adaptive immunity (165).

\subsubsection{Humoral Responses}

The mechanisms involving the humoral responses towards influenza virus have been well elucidated in recent decades. During infection, naïve $\mathrm{B}$ cells in the mesenteric lymph nodes $(\mathrm{mLN})$ encounter the influenza virus antigen and differentiate into antibody-forming cells (AFCs). Accordingly, B lymphocyte- deficient $\mu \mathrm{MT}$ mice showed high susceptibility to influenza virus infection compared to WT mice $(166,167)$. The B-cell response against influenza virus commences $\sim 3$ days post infection, meanwhile the anti-influenza virus IgG secretion begins by day 7. Systemic AFCs are first detected around 6-7 days postinfection (168), while the maximum number of B cells in bronchoalveolar lavage fluid (BALF) is observed around day 10 post-infection in mice (169). In mice, there is tissue-specific response of AFCs whereby they produce $\operatorname{IgG}$ and $\operatorname{IgM}$ in the lungs, and IgA in the upper respiratory tract (170).

The HA and NA proteins of the influenza virus are responsible for viral entry and release, therefore antibodies specific to these antigens are crucial for protective immunity. HA-specific antibodies result in viral neutralization through binding to the HA globular head and inhibiting the attachment of the virus to the host cell's surface (171-173). However, NAspecific antibodies inhibit the enzymatic activity of NA and instead block viral replication $(174,175)$. Further, M2 proteins have also been shown to be target of specific antibodies and passive transfer of M2-specific antibodies can provide protection against viral replication (176). Interestingly, NP-specific antibodies also facilitate resistance to influenza virus, despite targeting an internal influenza virus protein (177). In addition, the influenza virus-specific antibodies also mediate antibodydependent cell cytotoxicity and $F_{c}$ receptor-mediated phagocytosis, and thus significantly contribute to the clearance of infected cells (178). These antigen targets have been classically and effectively targeted with seasonal vaccinations against influenza, however efficacy per season has at times been insufficient (179). If there is no change to the antigen targeted, based on historical strategies, an alternative formulation or adjuvantation would be required for amplified protection.

\subsubsection{Cell-Mediated Immune Responses}

Naïve $\mathrm{CD}^{+} \mathrm{T}$ cells recognize the viral antigens presented by the MHC class II proteins on APCs, and subsequently differentiate into several types of helper $\mathrm{T}$ cells depending upon the cytokine milieu. This leads to activation and differentiation of antibodyproducing B cells via support from the activated $\mathrm{CD} 4^{+} \mathrm{T}$ cells, and induction of $\mathrm{CD}^{+} \mathrm{T}$ cells responses (Figure 1). In mice, the peak $\mathrm{CD} 4^{+} \mathrm{T}$ cell response is observed at 10 days post influenza infection (180). Adaptive transfer of effector $\mathrm{CD} 4^{+} \mathrm{T}$ cells isolated from mice infected with influenza demonstrated enhanced survival of recipient mice challenged with the virus (180). In particular, the cytokine milieu resulting from influenza virus infection is polarized towards generation of Th1 cells (181), which produce IFN $\gamma$, TNF and IL-2. This promotes activation of macrophages, production of IgG2a and IgG3 isotypes antibodies from B cells (182), and induction of cellular immune responses. Additionally, Th2 responses are also induced post influenza infection resulting in production of IL-4, IL-5 and IL-13 and isotype switching of B cells to produce other antibody isotypes i.e. IgG1 and IgE (181). However, survival after influenza virus infection is primarily correlated with Th1 compared to Th2 cells (183). Studies using influenza-infected mice have shown involvement of $\mathrm{CD} 4^{+} \mathrm{T}$ populations in perforin/ granzyme-mediated cytolytic activity $(181,184,185)$. Additionally, 
influenza virus infection leads to robust Tregs that mediate immunosuppression and tissue repair via amphiregulin and IL-10 $(186,187)$, and depletion of Tregs results in a reduction of the influenza-specific $\mathrm{T}_{\mathrm{FH}}$ response (188). Thus, highlighting the important role of Tregs in host protection during and after influenza virus infection.

$\mathrm{CD}^{+} \mathrm{T}$ cells recognize influenza viral antigens presented by MHC class I proteins on the surface of APCs and are crucial for viral clearance and host protection. $\mathrm{CD}^{+}$responses peak around $8^{\text {th }}$ day post-infection in the mLN and at $10^{\text {th }}$ day in BALF (169, 189). Mice lacking $\mathrm{CD}^{+} \mathrm{T}$ cells ( $\beta 2$-microglobulin-deficient mice) upon influenza viral challenge demonstrate delayed viral clearance and severe mortality (190). Activated cytotoxic CD8 ${ }^{+} \mathrm{T}$ cells (CTLs) eliminate virus-infected cells via cytolysis by producing perforin to permeabilize their membrane and secreting granzyme to induce apoptosis (175). In addition, CTLs can also kill infected host cells via TNF receptor familydependent pathways. CTLs express the Fas ligand (FasL) which binds to Fas on target cells and this interaction induces apoptosis via caspase-cascade activation. $\mathrm{CD}^{+} \mathrm{T}$ cells also express TNFrelated apoptosis-inducing ligand (TRAIL) responsible for $\mathrm{CD}^{+}$ T cell-mediated cytotoxicity (191). Effector $\mathrm{CD}^{+} \mathrm{T}$ cells produce TNF and IFN $\gamma$ in the lungs, which aids the viral defense mechanisms (192-194). Remarkably, these cells are also major producers of IL-10 which regulates pulmonary inflammation during response to the influenza virus infection. Moreover, even with sublethal influenza virus challenge blockade of IL-10 signaling augments pulmonary inflammation and lethal injury (195).

\subsection{Currently Licensed Influenza Vaccines} 4.3.1 Whole Inactivated Virus Vaccines

Although currently not in use due to high reactogenicity, whole inactivated virus vaccines are the easiest to generate and thus have been extensively used in humans as well as studied in animal models. Depending upon the inactivation method employed, inactivated viruses can represent antigens of live virus relatively well. Thus, these vaccines may potentially retain activity of HA and fusion of HA as well as NA activity. Additionally, whole inactivated virus vaccines also contain viral RNA which can activate multiple PRRs including TLR3, TLR7, TLR8 and RIG-I (196), thus resulting in a self-adjuvanting effect. These vaccines can induce a relatively balanced immune response, leading to a response to both $\mathrm{HA}$ and NA in humans as well as animal models, and relatively high seroprotection rates (>85\% in humans) (197-200). However, in terms of seroprotection and geometric mean HA inhibition (HAI) titers, whole inactivated virus vaccines did not demonstrate any additional benefit compared to split virus or subunit vaccines (201) and understanding of cell mediated responses in humans remain unclear.

\subsubsection{Split Virus and Subunit Vaccines}

Split virus or subunit vaccines are manufactured from whole inactivated virus which are treated with detergent and further purified. These vaccines are classified based upon the viral components incorporated after downstream purification process, preparation containing parts of the viral membrane carrying HA and NA, referred to as split virus vaccine, and with almost pure glycoprotein referred to as subunit vaccine. Notably, most of the viral RNA is removed during the purification process, which leads to reduced reactogenicity but might also leads to weakened immunogenicity. Moreover, the structural integrity of HA and NA proteins, as well preservation of crucial antibody-binding epitopes in these vaccines remains unclear. The immune response after vaccination with a split virus or subunit vaccines is typically targeted towards HA since the NA content of these vaccines is neither standardized nor detectable in certain cases (200).

The breadth of the humoral response to whole inactivated virus vaccines, split virus and subunit vaccines has been widely evaluated. In addition, these can induce cross-reactive antibody responses to historic virus strains in adults with pre-existing immunity $(201,202)$. However, they fail to induce significant titers of cross-reactive stalk-specific antibodies. Importantly, current split and subunit vaccines are inefficient in inducing cross-reactive $\mathrm{CD} 8^{+} \mathrm{T}$ cells, which would otherwise be elicited by natural influenza virus infection (203). In addition, vaccine effectiveness is markedly reduced due to antigenic mismatches between circulating virus and vaccine virus strains. Therefore, they tend to induce responses which are remarkably narrow and strain specific.

\subsubsection{Recombinant Hemagglutinin Vaccines}

Recombinant $\mathrm{HA}$ vaccines contain only $\mathrm{HA}$, therefore the immune response specifically targets HA. These vaccines typically contain higher doses of HA (up to $45 \mu \mathrm{g}$ per strain) compared to split or subunit vaccines, however the antibody responses generated are at least comparable to that induced by whole inactivated, subunit or split virus vaccines (204). Although recombinant HA vaccines were licensed only recently, they have been extensively studied in human clinical trials. Moreover, growing literature suggests that recombinant HA vaccines work particularly well in the elderly by inducing broader responses and providing better protection $(205,206)$. In a recent study, recombinant $\mathrm{HA}$ vaccine demonstrated superior HA-specific both antibody and $\mathrm{CD}^{+} \mathrm{T}$ cell responses in adult human cohorts when compared with inactivated influenza vaccine (207). Notably, since the HA is expressed recombinantly, these vaccines overcome mismatches that occur in regular vaccine seed strains due to adaptation of the influenza virus while cultured in eggs (208).

\subsubsection{Live-Attenuated Virus Vaccines}

The vaccines discussed above are typically either administrated intramuscularly or intradermally, however it remains unclear whether these routes of administration optimally induce mucosal immune response in the upper respiratory tract (209). The mucosal immunity induced through these vaccination routes in humans could be the result of priming by natural influenza virus infection. In contrast, live-attenuated virus vaccines which use a weakened (or attenuated) form of the virus are administered intranasally and promote replication of live attenuated influenza virus (LAIV) in the upper respiratory tract. Thus, the immune 
response to LAIVs is multifaceted which does not necessarily involve a serum antibody response, and LAIVs have been licensed based upon efficacy trials that measure protection rather than correlates of protection. Additionally, a study comparing long-term systemic and secretory antibody responses in children who were administered live, attenuated or inactivated influenza vaccine demonstrated LAIVs induce antibody responses which persist significantly longer (210). Multiple studies have shown enhanced efficacy of LAIVs in young children compared to inactivated vaccines $(211,212)$ whereby LAIVs have been shown to induce diverse $\mathrm{T}$-cell responses by inducing $\mathrm{CD}^{+}, \mathrm{CD}^{+}$and $\gamma \delta \mathrm{T}$ cells (213). In addition, in adults with extensive and partially cross-reactive preexisting influenza immunity LAIV has been shown to boost secretory IgA responses to HA and non-HA antigenic targets expressed by circulating influenza strains (214).

\subsubsection{Adjuvanted Influenza Vaccines}

Despite current influenza vaccines being immunogenic, evolution of the virus can reduce efficacy of the vaccines. Adjuvanted influenza vaccines incorporate adjuvants which can boost immune response. This is particularly beneficial for influenza vaccines administered during a pandemic when a rapid response is required or for use in vulnerable populations, such as infants and the elderly. Up until the early $21^{\text {st }}$ century, alum remained the only adjuvant included in licensed vaccine formulations, until, in 2015 MF59 (squalene emulsion) was incorporated into a licensed influenza vaccine designed for enhancing efficacy for the elderly populations in the USA (215). MF59 triggers effective and safe immunogenicity via Th2 skewed immune responses (216) and induces chemokines and cytokines, such as CCL2, CCL3 IL-8, and IL-5 (217), which enhance vaccine efficacy by triggering memory $\mathrm{B}$ cells and vaccine strain specific $\mathrm{CD}^{+} \mathrm{T}$ cells (218). Adjuvant system (AS) 03 is an oil-in-water adjuvant which acts similar to MF59 (215). MF59 and AS03 adjuvants also showed heterologous immune responses against non-vaccine influenza strains in human subjects (215). Thus, vaccine adjuvants embrace a numerous potential to achieve a universal flu vaccine by inducing cross-protective immunity.

\subsection{Lessons From Influenza Infection and Future Vaccine Strategies}

Development of a "universal vaccine" for influenza is challenging because seasonal vaccines lack efficacy against most circulating influenza strains due to antigenic variability. One of the current approaches for influenza vaccine development is to mimic the natural exposure via attenuated viral infection or viral vector administration which triggers natural immunity. Live attenuated licensed vaccine FluMist showed $70-90 \%$ efficacy over placebo in $1^{\text {st }}$ year and $47-80 \%$ efficacy in $2^{\text {nd }}$ year after immunization (219). FluMist promotes virus specific lung TRM and establishes longterm protection compared to inactivated attenuated formulation (220) and was proven safe in a surveillance study $(221,222) . \mathrm{CD}^{+}$ lung TRMs confer frontline defense and accumulate after viral reinfection, but response may wane overtime (223). As such, in depth understating of targeting and optimizing the effector activity of TRMs offers significant opportunity to achieve long-lasting protection (224). Attenuated influenza virus with adjuvant [MER4101, (cH8/1N1, H5/1N1)] or non-adjuvant (GHB11L1, GHB16L2, M2SR) and viral vector (Ad4-H5-Vtn, MVA-NP +M1, ChAdOx1-NP+M1, VXA-A1.1, GamFluVac) candidates are entered in human clinical trials in the last decade and currently in progress (225) to achieve an improved influenza vaccine. The "unnatural immunity" (16), which does not occur naturally may be achievable by triggering antibodies which do not elicit during the course of natural infection. Such lack of preexisting immunity could be restored by the adjuvantation approaches (226). TLR3 agonist- (dsRNA), TLR4 agonist(MPLA, GLA-AF, ND002), TLR5 agonist- (Vax128), TLR7 agonist- (Imiquimod) and TLR9 agonist- (CPG 7909) adjuvanted vaccine approaches are already in clinical trial (227). Of note, synthetic TLR7 agonist adjuvant, Imiquimod, induced improved influenza specific homologous and heterologous immunogenicity in a phase 3 trial (228). Micro and nano emulsion formulations like AS25, AS50, SE, Montanide ISA-51 are in phase 2 clinical trial and drove increased influenza specific immune responses (227). Immune protection could be boosted by the production of broadly neutralizing antibodies against influenza viruses by designing DNA vaccines (229). Recently developed mRNA-based vaccines have demonstrated great promise after proven efficacious against severe COVID-19 outcomes, including hospitalization and death. HA based mRNA vaccines are in clinical trials, as reviewed in (230) and may have some advantages over conventional inactivated influenza vaccines (231-233). Another approach is to develop a next generation influenza vaccine which triggers heterosubtypic or heterologous immunity (234). Such broad spectrum or non-strain specific vaccine design is feasible by identifying conserved protein regions shared among pre-pandemic and circulating strains via epitope mapping $(235,236)$. Identification of broadly reactive antigens can be considered as a reverse vaccinology approach which is going to be the most powerful tool for next generation vaccine designing (235). Newborns are particularly at increased risk of severe disease following influenza infection since they may be unable to mount an effective immune response to clear infection. However, a more in-depth understanding of protective responses generated during natural influenza infection can guide development of vaccines which illicit broader responses with limited reactogenicity in these vulnerable populations (237).

\section{TOOLKIT FOR PRECISION VACCINES TO MIMIC THE NATURAL IMMUNITY}

Based on current understanding of natural infection of MTB, BP and influenza, there are a number of strategies to mimic the immunological manifestation and incorporating it to develop the next generation vaccines (Figures 1C, 2). One major caveat relevant to all vaccination strategies targeting $\mathrm{MTB}, \mathrm{BP}$ and influenza is waning immunological memory. One approach to bypass it by triggering polyfunctional $\mathrm{T}$ cell responses or by 


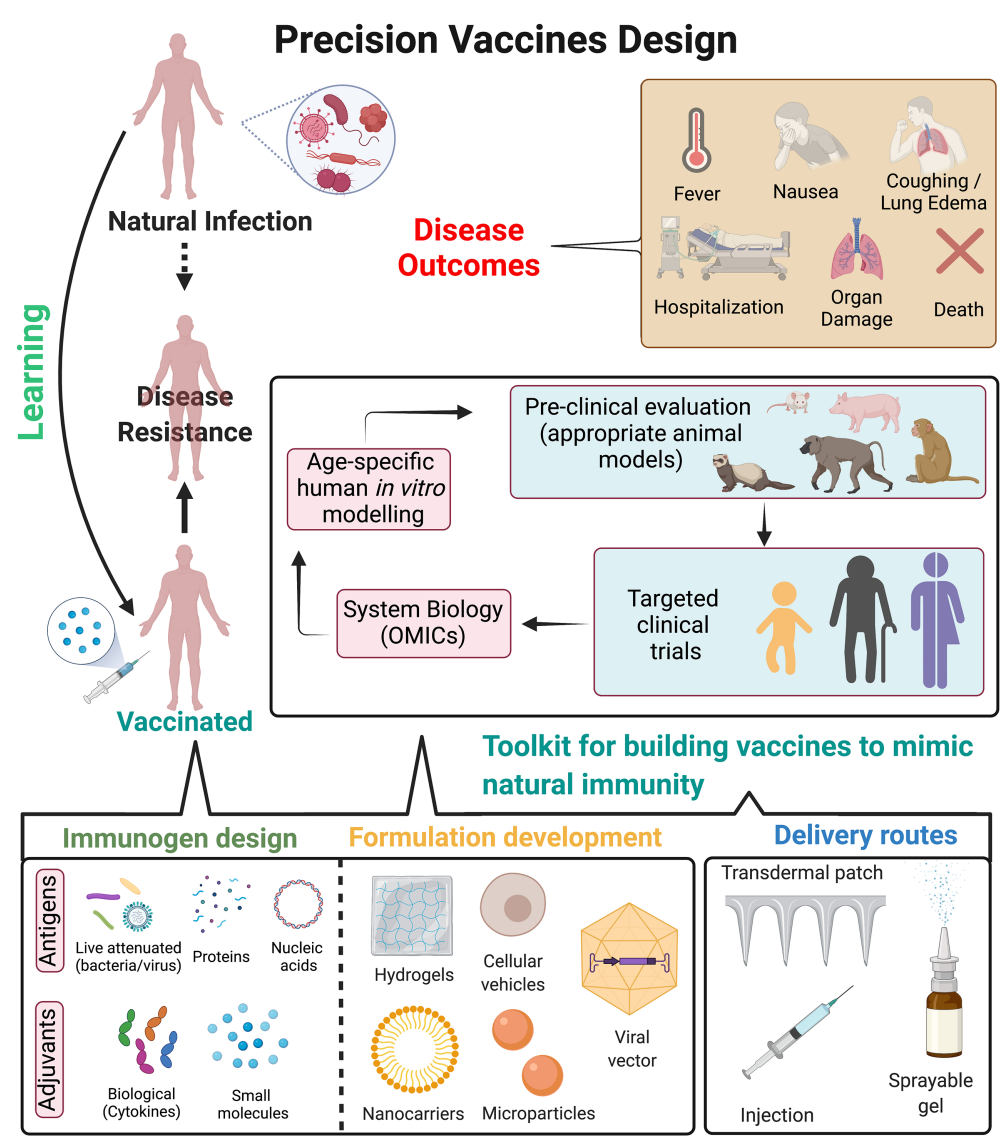

FIGURE 2 | Precision vaccines design. Overview of strategies to design precision vaccines which can effectively mimic immunity against pathogens as observed post natural infection. Natural infection often leads to immunological imprinting which provides long-term immunity and disease resistance to future exposure of pathogens. However, it can also lead to detrimental effects to the host as observed in disease outcomes. On the contrary, vaccination provides disease resistance but may be associated with waning immunity, insufficient protective immune response either in vulnerable populations or to prevent disease transmission, contraindications for immunocompromised hosts etc. Precision vaccines can guide the development of next generation vaccines by incorporating a toolkit for building vaccines to mimic natural immunity, which includes: i) immunogen design (such as antigens, small molecule TLR or other adjuvants, biological adjuvants such as cytokines); ii) optimizing formulations for targeted delivery to antigen presenting cells which can lead to subsequent long-lasting adaptive immune response (approaches such as hydrogels, cellular vehicles, nanocarriers and microparticles etc.); iii) optimizing delivery routes for enhancing immune response and mimicking the natural exposure to the pathogen (such as transdermal patch, injection site, sprayable gels for nasal routes) and iv) pre-clinical evaluation of vaccine formulations in appropriate animal models can be followed by clinical evaluation in distinct populations. System biology approaches from such clinical trials may be helpful to dissect age- and population specific vaccine-induced cellular and molecular signatures which correlate with protective immunity. Further, usage of human in vitro modelling may accelerate and/or expand hypothesis testing and selection of population specific adjuvants. These approaches can lead to precision vaccines tailored for long-term disease protection while abating disease outcomes associated with natural infection. Figure is created with BioRender.com.

inducing long-lived TRMs (Figure 1C). Clonal expansion of antigen specific memory $\mathrm{T}$ cells mainly depends on the interaction with antigen bearing DCs (238). Unique DC subsets can orchestrate these signals into appropriately regulated adaptive immune responses. Therefore, reprogramming the DC phenotypes (which must mimic the immunophenotype after natural infection) by precision vaccines would be a smart choice. Another strategy would be the fine tuning of the antigen specific $\mathrm{T}$ cell proliferation during their developmental phase by using precision vaccine technology $(238,239)$, such as TLR agonistsbased adjuvantation, many of which have the promising ability to drive phenotypic shifts of Th populations $(140,142)$. Overall, precision vaccinology can offer the fine tuning or reprogramming of DCs or APCs and antigen specific T cells. Antigen and adjuvant discovery, immunoengineering, vaccine delivery and more importantly increased understanding of human immune responses via dissecting the components of natural infection are fueling a revolution in vaccinology and guiding the development of precision vaccines $(3,240)$, especially for vulnerable infants (241) and older adults (242).

\subsection{Immunogen Design}

Conventional vaccine design (live attenuated bacteria/virusbased or protein-based vaccines) provides durable protection against several diseases. However, there remain major obstacles to vaccine development against a variety of pathogens, especially 
those better able to evade the adaptive immune response. Furthermore, for emerging virus vaccines, the primary hurdle is not the effectiveness of conventional approaches but the urgency for rapid development and large-scale deployment (243). Thus, as observed during the recent COVID-19 pandemic, the development of versatile vaccine platforms has become important (244). Vaccine platforms such as mRNAbased vaccines only require sequence information to trigger vaccine development, thereby increasing the flexibility to adapt vaccines to antigenic changes in circulating as well as new emerging strains. This aids in pre-emptive and reactive vaccine design, moreover faster development and manufacturing options, ultimately enhancing our ability to rapidly respond to emerging viruses (244). Lessons from natural infection can aid these novel vaccine platforms by precisely guiding the selection of immunogen as well as individual specific adjuvant for a more effective and durable vaccine response (Figure 2).

\subsection{Formulation}

Recent advances in the field of immunoengineering, which are evolving alongside vaccinology, have begun to greatly influence vaccine formulation design $(245,246)$. Due to the disparities in mechanisms of action of various non-adjuvanted and adjuvanted vaccines, vaccine formulation development has become a major consideration for vaccinologists and pharmaceutical companies (247). These factors include (1) physicochemical characteristics of the formulation, (2) adjuvant chemical structure and (3) short- and long-term formulation stability (246). Specifically, vaccine delivery systems have now evolved to mimic the shape, size, and surface chemistry of pathogens (248), which are often referred to as "pathogen-like particles". These vaccine formulations can thus allow control of antigen and adjuvant biodistribution, regulation of vaccine uptake by APCs, optimized triggering of antigen-specific B cells, and precisely influence vaccine kinetics (249).

\subsection{Delivery Route}

Most current vaccination procedures utilize needles and syringes which are administered through the intramuscular route of injection. However, studies in the recent decades have suggested that skin and mucosal membranes which are not accessible by conventional needles, are however the ideal targets for vaccine delivery $(250,251)$. The shortcomings of injections have led to active research and development for needle-free methods of immunization. Additionally, these alternate methods also reduce the risk of exposure to needle-borne infections, lower toxicity and economic costs, and ultimately enhance safety and reproducibility in large demographics. Although, each method offers advantages and contrarily limitations that may need to be overcome, understanding natural infection for a particular pathogen can help guide the optimal delivery route for maximal vaccine response (252).

\subsection{Clinical Evaluation}

Children, older adults and immunocompromised individuals are primary risk groups for $\mathrm{MTB}, \mathrm{BP}$ and influenza infection. As such, for vaccines designed to reduce transmission of respiratory infection in general, new vaccination strategies should also strive to take into consideration the target population, including for human immune ontogeny and clinical history. For example, demonstrated for influenza (253), exposure to circulating respiratory viruses may imprint a subsequent immune response, with unique $\mathrm{T}$ cell responses in early life. Better understanding of the effects of pathogenesis as intertwined with $\mathrm{T}$ cell ontogeny is beginning to elucidate more effective vaccine approaches for the induction of early life cell mediated immunity (254-256). Multidisciplinary approaches including standardized human in vitro models, systems vaccinology, and innovations of formulation and delivery systems will enhance identification of mechanisms of action and biomarkers of safety and efficacy of adjuvants and adjuvanted vaccines thereby accelerating and de-risking adjuvanted vaccine development $(82,257)$ (Figure 2). Successful stimulation of T cell responses by precision vaccine approaches has certain criteria: i) considering MHC diversity in human population, ii) targeting immunodominant epitopes (either by bioinformatics or by immunophenotyping approaches, iii) assessment method in vitro (either tetramer-based assay or targeted antigen stimulation) to evaluate co-relation of protection. There is also a growing interest in the possibility of trained-immunity based vaccines (TIbV), meant to enhance innate cross-protection to heterologous pathogens and to induce more efficient adaptive responses against the specific pathogens contained in the vaccine (258-264).

\section{CONCLUDING REMARKS}

Vaccines are one of the most cost-effective and effective interventions to address the global burden of pediatric infectious diseases and the implementation of early life immunizations has reduced deaths in neonates and children across the world (4). Infants are capable of inducing adaptive immune responses after pathogen exposure. Though immune responses may be suboptimal in early age but it could be adequately induced and effectively maintained after vaccination, under certain conditions (265). Due to aging, the elder immune system, especially the innate compartment, gradually wanes via the process of immunosenescence, also leaving this population vulnerable to infection (266). Due to such differences in the early life and later life adult immune systems, it is increasingly appreciated that an indepth understanding of early life immunity is crucial for the development of effective pediatric vaccines and for optimizing geriatric vaccine schedules. The human specific immunopathology leading to protective immunity to $\mathrm{MTB}, \mathrm{BP}$ and influenza are partially and potentially poorly characterized. Live attenuated vaccines generally provide more robust protective immunity than vaccines comprised of killed organisms. Innate detection of a signatures of microbial viability such as bacterial RNA has been shown to be acted as vita-PAMPs (74). As compared to non-viable pathogens, transient bacterial RNA induces $\mathrm{T}_{\mathrm{FH}}$ differentiation and enhanced humoral responses (267). Vaccine formulation like BCG or live attenuated BP vaccine strain (BPZE1) or the LAIV, which incorporate molecular signatures of microbial viability, have the potential to establish protective immunity against reinfection that may outperform protein-based vaccines. 
Furthermore, as immune responses induced by natural infection and pathogen specific vaccines often overlap, an important question remains to be addressed: should natural infection be used as a benchmark for optimal vaccine design, or should the ability of novel vaccines to induce a broad unnatural spectrum of immunity be the goal? Immunological imprinting, after the first influenza infection/s in early life for example, might influence vaccine efficiency by altering the immune response in post vaccination period (268). BCG vaccination imprints a persistent transcriptomic bias on human stem and progenitor cells toward the myeloid cell lineage which elicits beneficial trained immunity (71, 269), an added component of vaccine formulation only elucidated in the most recent decades. Therefore, it may be important to study the potential impact of immune imprinting by natural infections, but to also consider the role of induction of unnatural response to solve some of the most pressing and enduring problems of vaccine preventable and non-preventable diseases. These questions may help guide the vaccine design in $21^{\text {st }}$ century.

\section{AUTHOR CONTRIBUTIONS}

DD conceived the review article. SB, DS, BB and DD contributed to the writing. EN contributed to intellectual input and critical

\section{REFERENCES}

1. Angelidou A, Levy O. Vaccination of Term and Preterm Infants. Neoreviews (2020) 21(12):e817-27. doi: 10.1542/neo.21-12-e817

2. Soni D, Van Haren SD, Idoko OT, Evans JT, Diray-Arce J, Dowling DJ, et al. Towards Precision Vaccines: Lessons From the Second International Precision Vaccines Conference. Front Immunol (2020) 11:590373. doi: 10.3389/fimmu.2020.590373

3. Soni D, Bobbala S, Li S, Scott EA, Dowling DJ. The Sixth Revolution in Pediatric Vaccinology: Immunoengineering and Delivery Systems. Pediatr Res (2020) 89(6):1364-72. doi: 10.1038/s41390-020-01112-y

4. Plotkin S. History of Vaccination. Proc Natl Acad Sci USA (2014) 111 (34):12283-7. doi: 10.1073/pnas.1400472111

5. Orme IM, Henao-Tamayo MI. Trying to See the Forest Through the Trees: Deciphering the Nature of Memory Immunity to Mycobacterium Tuberculosis. Front Immunol (2018) 9:461. doi: 10.3389/fimmu.2018.00461

6. Kampmann B, Jones CE. Factors Influencing Innate Immunity and Vaccine Responses in Infancy. Philos Trans R Soc Lond B Biol Sci (2015) 370(1671). doi: 10.1098/rstb.2014.0148

7. Brook B, Harbeson D, Ben-Othman R, Viemann D, Kollmann TR. Newborn Susceptibility to Infection vs. Disease Depends on Complex In Vivo Interactions of Host and Pathogen. Semin Immunopathol (2017) 39 (6):615-25. doi: 10.1007/s00281-017-0651-z

8. Amanna IJ, Slifka MK. Successful Vaccines. Curr Top Microbiol Immunol (2020) 428:1-30. doi: 10.1007/82_2018_102

9. Dowling DJ. Early Life Immune Ontogeny - Understanding How We Build and Sustain Immunity to Infection. Perspect Public Health (2016) 136 (4):205-7. doi: 10.1177/1757913916641586

10. Kollmann TR, Kampmann B, Mazmanian SK, Marchant A, Levy O. Protecting the Newborn and Young Infant From Infectious Diseases: Lessons From Immune Ontogeny. Immunity (2017) 46(3):350-63. doi: 10.1016/j.immuni.2017.03.009

11. Dowling DJ, Levy O. Ontogeny of Early Life Immunity. Trends Immunol (2014) 35(7):299-310. doi: 10.1016/j.it.2014.04.007

12. Dowling DJ, Levy O. Pediatric Vaccine Adjuvants: Components of the Modern Vaccinologist's Toolbox. Pediatr Infect Dis J (2015) 34(12):1395-8. doi: 10.1097/INF.0000000000000893 review. All authors contributed to the article and approved the submitted version.

\section{FUNDING}

DD's laboratory is supported by NIH grant 5R21AI137932-02, Adjuvant Discovery Program contract \#75N93019C00044, Adjuvant Development Program contract \#272201800047C. The Precision Vaccines Program is supported in part by the BCH Department of Pediatrics and the Chief Scientific Office.

\section{ACKNOWLEDGMENTS}

The authors would like to thank Dr. Ofer Levy for his mentorship, and Boston Children's Hospital Precision Vaccines Program for publication support. DD would like to thank Siobhan McHugh, Geneva Boyer, Lucy Conetta and the staff of Lucy's Daycare, the staff of the YMCA of Greater Boston, Bridging Independent Living Together (BILT), Inc., and the Boston Public Schools for childcare and educational support during the COVID-19 pandemic. The authors would like to thank Alejandra Prevost-Reilly for proofreading the article.

13. Dowling DJ. Recent Advances in the Discovery and Delivery of TLR7/8 Agonists as Vaccine Adjuvants. Immunohorizons (2018) 2(6):185-97. doi: 10.4049/immunohorizons.1700063

14. Pulendran B, Davis MM. The Science and Medicine of Human Immunology. Science (2020) 369(6511). doi: 10.1126/science.aay4014

15. Jeyanathan M, Yao Y, Afkhami S, Smaill F, Xing Z. New Tuberculosis Vaccine Strategies: Taking Aim at Un-Natural Immunity. Trends Immunol (2018) 39(5):419-33. doi: 10.1016/j.it.2018.01.006

16. Nabel GJ, Fauci AS. Induction of Unnatural Immunity: Prospects for a Broadly Protective Universal Influenza Vaccine. Nat Med (2010) 16 (12):1389-91. doi: 10.1038/nm1210-1389

17. Kollmann TR, Marchant A, Way SS. Vaccination Strategies to Enhance Immunity in Neonates. Science (2020) 368(6491):612-5. doi: 10.1126/ science.aaz 9447

18. World Health Organization. Global Tuberculosis Report 2020. Geneva: WHO (2020).

19. Hatherill M, White RG, Hawn TR. Clinical Development of New TB Vaccines: Recent Advances and Next Steps. Front Microbiol (2019) 10:3154. doi: 10.3389/fmicb.2019.03154

20. Scriba TJ, Nemes E. Protection Against Tuberculosis by Mucosal BCG Administration. Nat Med (2019) 25(2):199-201. doi: 10.1038/s41591-0190347-0

21. Lai HH, Lai YJ, Yen YF. Association of Body Mass Index With Timing of Death During Tuberculosis Treatment. PloS One (2017) 12(1):e0170104. doi: 10.1371/journal.pone.0170104

22. Schrager LK, Vekemens J, Drager N, Lewinsohn DM, Olesen OF. The Status of Tuberculosis Vaccine Development. Lancet Infect Dis (2020) 20(3):e2837. doi: 10.1016/S1473-3099(19)30625-5

23. Andersen P, Scriba TJ. Moving Tuberculosis Vaccines From Theory to Practice. Nat Rev Immunol (2019) 19(9):550-62. doi: 10.1038/s41577-0190174-Z

24. Gupta N, Kumar R, Agrawal B. New Players in Immunity to Tuberculosis: The Host Microbiome, Lung Epithelium, and Innate Immune Cells. Front Immunol (2018) 9:709. doi: 10.3389/fimmu.2018.00709

25. Liu CH, Liu H, Ge B. Innate Immunity in Tuberculosis: Host Defense vs Pathogen Evasion. Cell Mol Immunol (2017) 14(12):963-75. doi: 10.1038/ cmi.2017.88 
26. Cervantes JL. MyD88 in Mycobacterium Tuberculosis Infection. Med Microbiol Immunol (2017) 206(3):187-93. doi: 10.1007/s00430-017-0495-0

27. Mortaz E, Adcock IM, Tabarsi P, Masjedi MR, Mansouri D, Velayati AA, et al. Interaction of Pattern Recognition Receptors With Mycobacterium Tuberculosis. J Clin Immunol (2015) 35(1):1-10. doi: 10.1007/s10875-014-0103-7

28. Faridgohar M, Nikoueinejad H. New Findings of Toll-Like Receptors Involved in Mycobacterium Tuberculosis Infection. Pathog Glob Health (2017) 111(5):256-64. doi: 10.1080/20477724.2017.1351080

29. Gong W, Liang Y, Wu X. The Current Status, Challenges, and Future Developments of New Tuberculosis Vaccines. Hum Vaccin Immunother (2018) 14(7):1697-716. doi: 10.1080/21645515.2018.1458806

30. Ferluga J, Yasmin H, Al-Ahdal MN, Bhakta S, Kishore U. Natural and Trained Innate Immunity Against Mycobacterium Tuberculosis. Immunobiology (2020) 225(3):151951. doi: 10.1016/j.imbio.2020.151951

31. Leopold Wager CM, Arnett E, Schlesinger LS. Mycobacterium Tuberculosis and Macrophage Nuclear Receptors: What We Do and Don't Know. Tuberculosis (Edinb) (2019) 116S:S98-106. doi: 10.1016/j.tube.2019.04.016

32. Collins AC, Cai H, Li T, Franco LH, Li XD, Nair VR, et al. Cyclic GMP-AMP Synthase Is an Innate Immune DNA Sensor for Mycobacterium Tuberculosis. Cell Host Microbe (2015) 17(6):820-8. doi: 10.1016/ j.chom.2015.05.005

33. Sia JK, Rengarajan J. Immunology of Mycobacterium Tuberculosis Infections. Microbiol Spectr (2019) 7(4). doi: 10.1128/microbiolspec.GPP30022-2018

34. Marinho FV, Benmerzoug S, Rose S, Campos PC, Marques JT, Bafica A, et al. The cGAS/STING Pathway Is Important for Dendritic Cell Activation But Is Not Essential to Induce Protective Immunity Against Mycobacterium Tuberculosis Infection. J Innate Immun (2018) 10(3):239-52. doi: 10.1159/ 000488952

35. de Martino M, Lodi L, Galli L, Chiappini E. Immune Response to Mycobacterium Tuberculosis: A Narrative Review. Front Pediatr (2019) 7:350. doi: 10.3389/fped.2019.00350

36. Tailleux L, Schwartz O, Herrmann JL, Pivert E, Jackson M, Amara A, et al. DC-SIGN Is the Major Mycobacterium Tuberculosis Receptor on Human Dendritic Cells. J Exp Med (2003) 197(1):121-7. doi: 10.1084/jem.20021468

37. Ardain A, Domingo-Gonzalez R, Das S, Kazer SW, Howard NC, Singh A, et al. Group 3 Innate Lymphoid Cells Mediate Early Protective Immunity Against Tuberculosis. Nature (2019) 570(7762):528-32. doi: 10.1038/ s41586-019-1276-2

38. Choreno-Parra JA, Weinstein LI, Yunis EJ, Zuniga J, Hernandez-Pando R. Thinking Outside the Box: Innate- and B Cell-Memory Responses as Novel Protective Mechanisms Against Tuberculosis. Front Immunol (2020) 11:226. doi: 10.3389/fimmu.2020.00226

39. Uehira K, Amakawa R, Ito T, Tajima K, Naitoh S, Ozaki Y, et al. Dendritic Cells Are Decreased in Blood and Accumulated in Granuloma in Tuberculosis. Clin Immunol (2002) 105(3):296-303. doi: 10.1006/ clim.2002.5287

40. Rodrigues TS, Conti BJ, Fraga-Silva TFC, Almeida F, Bonato VLD. Interplay Between Alveolar Epithelial and Dendritic Cells and Mycobacterium Tuberculosis. J Leukoc Biol (2020) 108(4):1139-56. doi: 10.1002/ JLB.4MR0520-112R

41. Kong XF, Martinez-Barricarte R, Kennedy J, Mele F, Lazarov T, Deenick EK, et al. Disruption of an Antimycobacterial Circuit Between Dendritic and Helper T Cells in Human SPPL2a Deficiency. Nat Immunol (2018) 19 (9):973-85. doi: 10.1038/s41590-018-0178-z

42. Vella LA, Herati RS, Wherry EJ. CD4(+) T Cell Differentiation in Chronic Viral Infections: The Tfh Perspective. Trends Mol Med (2017) 23(12):107287. doi: 10.1016/j.molmed.2017.10.001

43. Hashimoto M, Kamphorst AO, Im SJ, Kissick HT, Pillai RN, Ramalingam SS, et al. CD8 T Cell Exhaustion in Chronic Infection and Cancer: Opportunities for Interventions. Annu Rev Med (2018) 69:301-18. doi: 10.1146/annurev-med-012017-043208

44. Im SJ, Ha SJ. Re-Defining T-Cell Exhaustion: Subset, Function, and Regulation. Immune Netw (2020) 20(1):e2. doi: 10.4110/in.2020.20.e2

45. Kronenberg M. Zajonc DM. A 'GEM' of a Cell. Nat Immunol (2013) 14 (7):694-5. doi: 10.1038/ni.2644

46. Harari A, Rozot V, Bellutti Enders F, Perreau M, Stalder JM, Nicod LP, et al. Dominant TNF-Alpha+ Mycobacterium Tuberculosis-Specific CD4+ T Cell
Responses Discriminate Between Latent Infection and Active Disease. Nat Med (2011) 17(3):372-6. doi: 10.1038/nm.2299

47. Jasenosky LD, Scriba TJ, Hanekom WA, Goldfeld AE. T Cells and Adaptive Immunity to Mycobacterium Tuberculosis in Humans. Immunol Rev (2015) 264(1):74-87. doi: 10.1111/imr.12274

48. Day CL, Abrahams DA, Lerumo L, Janse van Rensburg E, Stone L, O’Rie T, et al. Functional Capacity of Mycobacterium Tuberculosis-Specific T Cell Responses in Humans Is Associated With Mycobacterial Load. J Immunol (2011) 187(5):2222-32. doi: 10.4049/jimmunol.1101122

49. Prezzemolo T, Guggino G, La Manna MP, Di Liberto D, Dieli F, Caccamo N. Functional Signatures of Human CD4 and CD8 T Cell Responses to Mycobacterium Tuberculosis. Front Immunol (2014) 5:180. doi: 10.3389/ fimmu.2014.00180

50. Fletcher HA, Snowden MA, Landry B, Rida W, Satti I, Harris SA, et al. TCell Activation Is an Immune Correlate of Risk in BCG Vaccinated Infants. Nat Commun (2016) 7:11290. doi: 10.1038/ncomms11290

51. Ahmed A, Vyakarnam A. Emerging Patterns of Regulatory T Cell Function in Tuberculosis. Clin Exp Immunol (2020) 202(3):273-87. doi: 10.1111/ cei. 13488

52. Coulter F, Parrish A, Manning D, Kampmann B, Mendy J, Garand M, et al. IL-17 Production From T Helper 17, Mucosal-Associated Invariant T, and Gammadelta Cells in Tuberculosis Infection and Disease. Front Immunol (2017) 8:1252. doi: 10.3389/fimmu.2017.01252

53. Sable SB, Posey JE, Scriba TJ. Tuberculosis Vaccine Development: Progress in Clinical Evaluation. Clin Microbiol Rev (2019) 33(1). doi: 10.1128/ CMR.00100-19

54. Lu YJ, Barreira-Silva P, Boyce S, Powers J, Cavallo K, Behar SM. CD4 T Cell Help Prevents CD8 T Cell Exhaustion and Promotes Control of Mycobacterium Tuberculosis Infection. Cell Rep (2021) 36(11):109696. doi: 10.1016/j.celrep.2021.109696

55. Harris LD, Khayumbi J, Ongalo J, Sasser LE, Tonui J, Campbell A, et al. Distinct Human NK Cell Phenotypes and Functional Responses to Mycobacterium Tuberculosis in Adults From TB Endemic and NonEndemic Regions. Front Cell Infect Microbiol (2020) 10:120. doi: 10.3389/ fcimb. 2020.00120

56. Wagstaffe HR, Mooney JP, Riley EM, Goodier MR. Vaccinating for Natural Killer Cell Effector Functions. Clin Transl Immunol (2018) 7(1):e1010. doi: $10.1002 /$ cti2.1010

57. O'Garra A, Redford PS, McNab FW, Bloom CI, Wilkinson RJ, Berry MP. The Immune Response in Tuberculosis. Annu Rev Immunol (2013) 31:475527. doi: 10.1146/annurev-immunol-032712-095939

58. Martinot AJ, Blass E, Yu J, Aid M, Mahrokhian SH, Cohen SB, et al. Protective Efficacy of an Attenuated Mtb DeltaLprG Vaccine in Mice. PloS Pathog (2020) 16(12):e1009096. doi: 10.1371/journal.ppat.1009096

59. Rijnink WF, Ottenhoff THM. Joosten SA. B-Cells and Antibodies as Contributors to Effector Immune Responses in Tuberculosis. Front Immunol (2021) 12:640168. doi: 10.3389/fimmu.2021.640168

60. Lu LL, Smith MT, Yu KKQ, Luedemann C, Suscovich TJ, Grace PS, et al. IFN-Gamma-Independent Immune Markers of Mycobacterium Tuberculosis Exposure. Nat Med (2019) 25(6):977-87. doi: 10.1038/ s41591-019-0441-3

61. Joosten SA, Ottenhoff THM, Lewinsohn DM, Hoft DF, Moody DB, Seshadri C, et al. Harnessing Donor Unrestricted T-Cells for New Vaccines Against Tuberculosis. Vaccine (2019) 37(23):3022-30. doi: 10.1016/j.vaccine.2019.04.050

62. James CA. Seshadri C. T Cell Responses to Mycobacterial Glycolipids: On the Spectrum of "Innateness". Front Immunol (2020) 11:170. doi: 10.3389/ fimmu.2020.00170

63. Zeng G, Zhang G, Chen X. Th1 Cytokines, True Functional Signatures for Protective Immunity Against TB? Cell Mol Immunol (2018) 15(3):206-15. doi: $10.1038 / \mathrm{cmi} .2017 .113$

64. Darrah PA, DiFazio RM, Maiello P, Gideon HP, Myers AJ, Rodgers MA, et al. Boosting BCG With Proteins or Rad5 Does Not Enhance Protection Against Tuberculosis in Rhesus Macaques. NPJ Vaccines (2019) 4:21. doi: 10.1038/s41541-019-0113-9

65. Yang Q, Zhang M, Chen Q, Chen W, Wei C, Qiao K, et al. Cutting Edge: Characterization of Human Tissue-Resident Memory T Cells at Different Infection Sites in Patients With Tuberculosis. J Immunol (2020) 204 (9):2331-6. doi: 10.4049/jimmunol.1901326 
66. Ogongo P, Tezera LB, Ardain A, Nhamoyebonde S, Ramsuran D, Singh A, et al. Tissue-Resident-Like CD4+ T Cells Secreting IL-17 Control Mycobacterium Tuberculosis in the Human Lung. J Clin Invest (2021) 131 (10). doi: 10.1172/JCI142014

67. Roy A, Eisenhut M, Harris RJ, Rodrigues LC, Sridhar S, Habermann S, et al. Effect of BCG Vaccination Against Mycobacterium Tuberculosis Infection in Children: Systematic Review and Meta-Analysis. BMJ (2014) 349:g4643. doi: 10.1136/bmj.g4643

68. Zenteno-Cuevas R. Successes and Failures in Human Tuberculosis Vaccine Development. Expert Opin Biol Ther (2017) 17(12):1481-91. doi: 10.1080/ 14712598.2017.1378641

69. Tang J, Yam WC, Chen Z. Mycobacterium Tuberculosis Infection and Vaccine Development. Tuberculosis (Edinb) (2016) 98:30-41. doi: 10.1016/ j.tube.2016.02.005

70. Ernst JD. Mechanisms of M. Tuberculosis Immune Evasion as Challenges to TB Vaccine Design. Cell Host Microbe (2018) 24(1):34-42. doi: 10.1016/ j.chom.2018.06.004

71. Brook B, Harbeson DJ, Shannon CP, Cai B, He D, Ben-Othman R, et al. BCG Vaccination-Induced Emergency Granulopoiesis Provides Rapid Protection From Neonatal Sepsis. Sci Transl Med (2020) 12(542). doi: 10.1126/ scitranslmed.aax 4517

72. Angelidou A, Conti MG, Diray-Arce J, Benn CS, Shann F, Netea MG, et al. Licensed Bacille Calmette-Guerin (BCG) Formulations Differ Markedly in Bacterial Viability, RNA Content and Innate Immune Activation. Vaccine (2020) 38(9):2229-40. doi: 10.1016/j.vaccine.2019.11.060

73. Angelidou A, Diray-Arce J, Conti MG, Smolen KK, van Haren SD, Dowling DJ, et al. BCG as a Case Study for Precision Vaccine Development: Lessons From Vaccine Heterogeneity, Trained Immunity, and Immune Ontogeny. Front Microbiol (2020) 11:332. doi: 10.3389/fmicb.2020.00332

74. Ugolini M, Gerhard J, Burkert S, Jensen KJ, Georg P, Ebner F, et al. Recognition of Microbial Viability via TLR8 Drives TFH Cell Differentiation and Vaccine Responses. Nat Immunol (2018) 19(4):386-96. doi: 10.1038/s41590-018-0068-4

75. Van Der Meeren O, Hatherill M, Nduba V, Wilkinson RJ, Muyoyeta M, Van Brakel E, et al. Phase 2b Controlled Trial of M72/AS01E Vaccine to Prevent Tuberculosis. N Engl J Med (2018) 379(17):1621-34. doi: 10.1056/NEJMoa1803484

76. Van Maele L, Fougeron D, Cayet D, Chalon A, Piccioli D, Collignon C, et al. Toll-Like Receptor 4 Signaling in Hematopoietic-Lineage Cells Contributes to the Enhanced Activity of the Human Vaccine Adjuvant AS01. Eur J Immunol (2019) 49(12):2134-45. doi: 10.1002/eji.201948234

77. Blander JM, Barbet G. Exploiting Vita-PAMPs in Vaccines. Curr Opin Pharmacol (2018) 41:128-36. doi: 10.1016/j.coph.2018.05.012

78. Andersen P, Doherty TM. The Success and Failure of BCG - Implications for a Novel Tuberculosis Vaccine. Nat Rev Microbiol (2005) 3(8):656-62. doi: $10.1038 /$ nrmicrol211

79. Nemes E, Geldenhuys H, Rozot V, Rutkowski KT, Ratangee F, Bilek N, et al. Prevention of M. Tuberculosis Infection With H4:IC31 Vaccine or BCG Revaccination. N Engl J Med (2018) 379(2):138-49. doi: 10.1056/ NEJMoa1714021

80. Covian C, Fernandez-Fierro A, Retamal-Diaz A, Diaz FE, Vasquez AE, Lay MK, et al. BCG-Induced Cross-Protection and Development of Trained Immunity: Implication for Vaccine Design. Front Immunol (2019) 10:2806. doi: 10.3389/fimmu.2019.02806

81. Scheid A, Borriello F, Pietrasanta C, Christou H, Diray-Arce J, Pettengill MA, et al. Adjuvant Effect of Bacille Calmette-Guerin on Hepatitis B Vaccine Immunogenicity in the Preterm and Term Newborn. Front Immunol (2018) 9:29. doi: 10.3389/fimmu.2018.00029

82. Dowling DJ, Scott EA, Scheid A, Bergelson I, Joshi S, Pietrasanta C, et al. Toll-Like Receptor 8 Agonist Nanoparticles Mimic Immunomodulating Effects of the Live BCG Vaccine and Enhance Neonatal Innate and Adaptive Immune Responses. J Allergy Clin Immunol (2017) 140(5):133950. doi: 10.1016/j.jaci.2016.12.985

83. Joosten SA, van Meijgaarden KE, Arend SM, Prins C, Oftung F, Korsvold GE, et al. Mycobacterial Growth Inhibition Is Associated With Trained Innate Immunity. J Clin Invest (2018) 128(5):1837-51. doi: 10.1172/JCI97508

84. Kirman JR, Henao-Tamayo MI, Agger EM. The Memory Immune Response to Tuberculosis. Microbiol Spectr (2016) 4(6). doi: 10.1128/ microbiolspec.ТВTB2-0009-2016
85. Nieuwenhuizen NE, Kulkarni PS, Shaligram U, Cotton MF, Rentsch CA, Eisele B, et al. The Recombinant Bacille Calmette-Guerin Vaccine VPM1002: Ready for Clinical Efficacy Testing. Front Immunol (2017) 8:1147. doi: 10.3389 /fimmu.2017.01147

86. Woodland DL, Kohlmeier JE. Migration, Maintenance and Recall of Memory T Cells in Peripheral Tissues. Nat Rev Immunol (2009) 9(3):15361. doi: $10.1038 /$ nri2496

87. Tanner R, Villarreal-Ramos B, Vordermeier HM, McShane H. The Humoral Immune Response to BCG Vaccination. Front Immunol (2019) 10:1317. doi: 10.3389/fimmu.2019.01317

88. Chen T, Blanc C, Eder AZ, Prados-Rosales R, Souza AC, Kim RS, et al. Association of Human Antibodies to Arabinomannan With Enhanced Mycobacterial Opsonophagocytosis and Intracellular Growth Reduction. J Infect Dis (2016) 214(2):300-10. doi: 10.1093/infdis/jiw141

89. Sebina I, Cliff JM, Smith SG, Nogaro S, Webb EL, Riley EM, et al. Long-Lived Memory B-Cell Responses Following BCG Vaccination. PloS One (2012) 7 (12):e51381. doi: 10.1371/journal.pone.0051381

90. Basile JI, Liu R, Mou W, Gao Y, Carow B, Rottenberg ME. MycobacteriaSpecific T Cells Are Generated in the Lung During Mucosal BCG Immunization or Infection With Mycobacterium Tuberculosis. Front Immunol (2020) 11:566319. doi: 10.3389/fimmu.2020.566319

91. Bull NC, Stylianou E, Kaveh DA, Pinpathomrat N, Pasricha J, HarringtonKandt R, et al. Enhanced Protection Conferred by Mucosal BCG Vaccination Associates With Presence of Antigen-Specific Lung TissueResident PD-1(+) KLRG1(-) CD4(+) T Cells. Mucosal Immunol (2019) 12 (2):555-64. doi: 10.1038/s41385-018-0109-1

92. Wu Q, Kang S, Huang J, Wan S, Yang B, Wu C. Antigen-Specific TissueResident Memory $\mathrm{T}$ Cells in the Respiratory System Were Generated Following Intranasal Vaccination of Mice With BCG. J Immunol Res (2021) 2021:6660379. doi: 10.1155/2021/6660379

93. Barry CE3rd, Boshoff HI, Dartois V, Dick T, Ehrt S, Flynn J, et al. The Spectrum of Latent Tuberculosis: Rethinking the Biology and Intervention Strategies. Nat Rev Microbiol (2009) 7(12):845-55. doi: 10.1038/ nrmicro2236

94. Qiu X, Wang H, Tang Y, Su X, Ge L, Qu Y, et al. Is Interleukin-2 an Optimal Marker for Diagnosing Tuberculosis Infection? A Systematic Review and Meta-Analysis. Ann Med (2020) 52(7):376-85. doi: 10.1080/ 07853890.2020 .1800073

95. Morgan J, Muskat K, Tippalagama R, Sette A, Burel J, Lindestam Arlehamn CS. Classical CD4 T Cells as the Cornerstone of Antimycobacterial Immunity. Immunol Rev (2021) 301(1):10-29. doi: 10.1111/imr.12963

96. Doerks T, van Noort V, Minguez P, Bork P. Annotation of the M. Tuberculosis Hypothetical Orfeome: Adding Functional Information to More Than Half of the Uncharacterized Proteins. PloS One (2012) 7(4): e34302. doi: 10.1371/journal.pone.0034302

97. Mendez-Samperio P. Development of Tuberculosis Vaccines in Clinical Trials: Current Status. Scand J Immunol (2018) 88(4):e12710. doi: 10.1111/ sji. 12710

98. Blanc L, Gilleron M, Prandi J, Song OR, Jang MS, Gicquel B, et al. Mycobacterium Tuberculosis Inhibits Human Innate Immune Responses via the Production of TLR2 Antagonist Glycolipids. Proc Natl Acad Sci USA (2017) 114(42):11205-10. doi: 10.1073/pnas.1707840114

99. Tameris MD, Hatherill M, Landry BS, Scriba TJ, Snowden MA, Lockhart S, et al. Safety and Efficacy of MVA85A, a New Tuberculosis Vaccine, in Infants Previously Vaccinated With BCG: A Randomised, PlaceboControlled Phase 2b Trial. Lancet (2013) 381(9871):1021-8. doi: 10.1016/ S0140-6736(13)60177-4

100. Kaufmann SHE. Vaccination Against Tuberculosis: Revamping BCG by Molecular Genetics Guided by Immunology. Front Immunol (2020) 11:316. doi: $10.3389 /$ fimmu.2020.00316

101. Whitlow E, Mustafa AS, Hanif SNM. An Overview of the Development of New Vaccines for Tuberculosis. Vaccines (Basel) (2020) 8(4). doi: 10.3390/ vaccines 8040586

102. Enriquez AB, Izzo A, Miller SM, Stewart EL, Mahon RN, Frank DJ, et al. Advancing Adjuvants for Mycobacterium Tuberculosis Therapeutics. Front Immunol (2021) 12:740117. doi: 10.3389/fimmu.2021.740117

103. Fan XY, Lowrie DB. Where Are the RNA Vaccines for TB? Emerg Microbes Infect (2021) 10(1):1217-8. doi: 10.1080/22221751.2021.1935328 
104. Nieves DJ, Heininger U. Bordetella Pertussis. Microbiol Spectr (2016) 4(3). doi: 10.1128/microbiolspec.EI10-0008-2015

105. Zlamy M. Rediscovering Pertussis. Front Pediatr (2016) 4:52. doi: 10.3389/ fped.2016.00052

106. Fedele G, Bianco M, Ausiello CM. The Virulence Factors of Bordetella Pertussis: Talented Modulators of Host Immune Response. Arch Immunol Ther Exp (Warsz) (2013) 61(6):445-57. doi: 10.1007/s00005-013-0242-1

107. Hovingh ES, van Gent M, Hamstra HJ, Demkes M, Mooi FR, Pinelli E. Emerging Bordetella Pertussis Strains Induce Enhanced Signaling of Human Pattern Recognition Receptors TLR2, NOD2 and Secretion of IL-10 by Dendritic Cells. PloS One (2017) 12(1):e0170027. doi: 10.1371/journal.pone.0170027

108. Fedele G, Cassone A, Ausiello CM. T-Cell Immune Responses to Bordetella Pertussis Infection and Vaccination. Pathog Dis (2015) 73(7). doi: 10.1093/ femspd/ftv051

109. Brummelman J, Wilk MM, Han WG, van Els CA, Mills KH. Roads to the Development of Improved Pertussis Vaccines Paved by Immunology. Pathog Dis (2015) 73(8):ftv067. doi: 10.1093/femspd/ftv067

110. Asgarian-Omran H, Amirzargar AA, Zeerleder S, Mahdavi M, van Mierlo G, Solati S, et al. Interaction of Bordetella Pertussis Filamentous Hemagglutinin With Human TLR2: Identification of the TLR2-Binding Domain. APMIS (2015) 123(2):156-62. doi: 10.1111/apm.12332

111. Jurnecka D, Man P, Sebo P, Bumba L. Bordetella Pertussis and Bordetella Bronchiseptica Filamentous Hemagglutinins Are Processed at Different Sites. FEBS Open Bio (2018) 8(8):1256-66. doi: 10.1002/2211-5463.12474

112. Dewan KK, Linz B, DeRocco SE, Harvill ET. Acellular Pertussis Vaccine Components: Today and Tomorrow. Vaccines (Basel) (2020) 8(2). doi: $10.3390 /$ vaccines 8020217

113. Fedele G, Schiavoni I, Adkins I, Klimova N, Sebo P. Invasion of Dendritic Cells, Macrophages and Neutrophils by the Bordetella Adenylate Cyclase Toxin: A Subversive Move to Fool Host Immunity. Toxins (Basel) (2017) 9 (10). doi: 10.3390/toxins 9100293

114. Ryan M, Murphy G, Gothefors L, Nilsson L, Storsaeter J, Mills KH. Bordetella Pertussis Respiratory Infection in Children Is Associated With Preferential Activation of Type $1 \mathrm{~T}$ Helper Cells. J Infect Dis (1997) 175 (5):1246-50. doi: 10.1086/593682

115. van Twillert I, Han WG, van Els CA. Waning and Aging of Cellular Immunity to Bordetella Pertussis. Pathog Dis (2015) 73(8):ftv071. doi: 10.1093/femspd/ftv071

116. Kapil P, Merkel TJ. Pertussis Vaccines and Protective Immunity. Curr Opin Immunol (2019) 59:72-8. doi: 10.1016/j.coi.2019.03.006

117. Zurita ME, Wilk MM, Carriquiriborde F, Bartel E, Moreno G, Misiak A, et al. A Pertussis Outer Membrane Vesicle-Based Vaccine Induces Lung-Resident Memory CD4 T Cells and Protection Against Bordetella Pertussis, Including Pertactin Deficient Strains. Front Cell Infect Microbiol (2019) 9:125. doi: $10.3389 /$ fcimb.2019.00125

118. Wilk MM, Borkner L, Misiak A, Curham L, Allen AC, Mills KHG. Immunization With Whole Cell But Not Acellular Pertussis Vaccines Primes CD4 TRM Cells That Sustain Protective Immunity Against Nasal Colonization With Bordetella Pertussis. Emerg Microbes Infect (2019) 8 (1):169-85. doi: 10.1080/22221751.2018.1564630

119. Lambert EE, Buisman AM, van Els C. Superior B. Pertussis Specific CD4+ TCell Immunity Imprinted by Natural Infection. Adv Exp Med Biol (2019) 1183:81-98. doi: 10.1007/5584_2019_405

120. Kroes MM, Mariman R, Hijdra D, Hamstra HJ, van Boxtel K, van Putten JPM, et al. Activation of Human NK Cells by Bordetella Pertussis Requires Inflammasome Activation in Macrophages. Front Immunol (2019) 10:2030. doi: 10.3389/fimmu.2019.02030

121. Eby JC, Hoffman CL, Gonyar LA, Hewlett EL. Review of the Neutrophil Response to Bordetella Pertussis Infection. Pathog Dis (2015) 73(9):ftv081. doi: 10.1093/femspd/ftv081

122. Argondizo-Correia C, Rodrigues AKS, de Brito CA. Neonatal Immunity to Bordetella Pertussis Infection and Current Prevention Strategies. J Immunol Res (2019) 2019:7134168. doi: 10.1155/2019/7134168

123. Bancroft T, Dillon MB, da Silva Antunes R, Paul S, Peters B, Crotty S, et al. Th1 Versus Th2 T Cell Polarization by Whole-Cell and Acellular Childhood Pertussis Vaccines Persists Upon Re-Immunization in Adolescence and Adulthood. Cell Immunol (2016) 304-305:35-43. doi: 10.1016/ j.cellimm.2016.05.002
124. Lapidot R, Gill CJ. The Pertussis Resurgence: Putting Together the Pieces of the Puzzle. Trop Dis Travel Med Vaccines (2016) 2:26. doi: 10.1186/s40794016-0043-8

125. Barlow WE, Davis RL, Glasser JW, Rhodes PH, Thompson RS, Mullooly JP, et al. The Risk of Seizures After Receipt of Whole-Cell Pertussis or Measles, Mumps, and Rubella Vaccine. N Engl J Med (2001) 345(9):656-61. doi: 10.1056/NEJMoa003077

126. Dorji D, Mooi F, Yantorno O, Deora R, Graham RM, Mukkur TK. Bordetella Pertussis Virulence Factors in the Continuing Evolution of Whooping Cough Vaccines for Improved Performance. Med Microbiol Immunol (2018) 207(1):3-26. doi: 10.1007/s00430-017-0524-z

127. Cauchi S, Locht C. Non-Specific Effects of Live Attenuated Pertussis Vaccine Against Heterologous Infectious and Inflammatory Diseases. Front Immunol (2018) 9:2872. doi: 10.3389/fimmu.2018.02872

128. Mills KH, Ross PJ, Allen AC, Wilk MM. Do We Need a New Vaccine to Control the Re-Emergence of Pertussis? Trends Microbiol (2014) 22(2):4952. doi: 10.1016/j.tim.2013.11.007

129. Plotkin SA. The Pertussis Problem. Clin Infect Dis (2014) 58(6):830-3. doi: $10.1093 / \mathrm{cid} / \mathrm{cit} 934$

130. Cherry JD. The 112-Year Odyssey of Pertussis and Pertussis VaccinesMistakes Made and Implications for the Future. J Pediatr Infect Dis Soc (2019) 8(4):334-41. doi: 10.1093/jpids/piz005

131. Higgs R, Higgins SC, Ross PJ, Mills KH. Immunity to the Respiratory Pathogen Bordetella Pertussis. Mucosal Immunol (2012) 5(5):485-500. doi: $10.1038 / \mathrm{mi} .2012 .54$

132. Raeven RH, van der Maas L, Tilstra W, Uittenbogaard JP, Bindels TH, Kuipers B, et al. Immunoproteomic Profiling of Bordetella Pertussis Outer Membrane Vesicle Vaccine Reveals Broad and Balanced Humoral Immunogenicity. J Proteome Res (2015) 14(7):2929-42. doi: 10.1021/ acs.jproteome.5b00258

133. Dubois V, Chatagnon J, Thiriard A, Bauderlique-Le Roy H, Debrie AS, Coutte L, et al. Suppression of Mucosal Th17 Memory Responses by Acellular Pertussis Vaccines Enhances Nasal Bordetella Pertussis Carriage. NPJ Vaccines (2021) 6(1):6. doi: 10.1038/s41541-020-00270-8

134. da Silva Antunes R, Babor M, Carpenter C, Khalil N, Cortese M, Mentzer AJ, et al. Th1/Th17 Polarization Persists Following Whole-Cell Pertussis Vaccination Despite Repeated Acellular Boosters. J Clin Invest (2018) 128 (9):3853-65. doi: 10.1172/JCI121309

135. van der Lee S, Hendrikx LH, Sanders EAM, Berbers GAM, Buisman AM. Whole-Cell or Acellular Pertussis Primary Immunizations in Infancy Determines Adolescent Cellular Immune Profiles. Front Immunol (2018) 9:51. doi: 10.3389/fimmu.2018.00051

136. Lambert EE, Corbiere V, van Gaans-van den Brink JAM, Duijst M, Venkatasubramanian PB, Simonetti E, et al. Uncovering Distinct Primary Vaccination-Dependent Profiles in Human Bordetella Pertussis Specific CD4+ T-Cell Responses Using a Novel Whole Blood Assay. Vaccines (Basel) (2020) 8(2). doi: 10.3390/vaccines8020225

137. Warfel JM, Zimmerman LI, Merkel TJ. Acellular Pertussis Vaccines Protect Against Disease But Fail to Prevent Infection and Transmission in a Nonhuman Primate Model. Proc Natl Acad Sci USA (2014) 111(2):787-92. doi: 10.1073/pnas.1314688110

138. Esposito S, Stefanelli P, Fry NK, Fedele G, He Q, Paterson P, et al. Pertussis Prevention: Reasons for Resurgence, and Differences in the Current Acellular Pertussis Vaccines. Front Immunol (2019) 10:1344. doi: 10.3389/fimmu.2019.01344

139. Ong GH, Lian BSX, Kawasaki T, Kawai T. Exploration of Pattern Recognition Receptor Agonists as Candidate Adjuvants. Front Cell Infect Microbiol (2021) 11:745016. doi: 10.3389/fcimb.2021.745016

140. Chasaide CN, Mills KHG. Next-Generation Pertussis Vaccines Based on the Induction of Protective T Cells in the Respiratory Tract. Vaccines (Basel) (2020) 8(4). doi: 10.3390/vaccines8040621

141. Misiak A, Leuzzi R, Allen AC, Galletti B, Baudner BC, D'Oro U, et al. Addition of a TLR7 Agonist to an Acellular Pertussis Vaccine Enhances Th1 and Th17 Responses and Protective Immunity in a Mouse Model. Vaccine (2017) 35(39):5256-63. doi: 10.1016/j.vaccine.2017.08.009

142. Damron FH, Barbier M, Dubey P, Edwards KM, Gu XX, Klein NP, et al. Overcoming Waning Immunity in Pertussis Vaccines: Workshop of the National Institute of Allergy and Infectious Diseases. J Immunol (2020) 205 (4):877-82. doi: 10.4049/jimmunol.2000676 
143. Dowling DJ, Smith AJ, Borriello F, Brightman S, Schüller S, Bazin H, et al. Age-Specific TLR7/8 Adjuvant Formulation Overcomes Hyporesponsiveness to Neonatal Acellular Pertussis Vaccination in a Mouse Model. J Immunol (2018) 200(1 Supplement):180.24-.24.

144. Dunne A, Mielke LA, Allen AC, Sutton CE, Higgs R, Cunningham CC, et al. A Novel TLR2 Agonist From Bordetella Pertussis Is a Potent Adjuvant That Promotes Protective Immunity With an Acellular Pertussis Vaccine. Mucosal Immunol (2015) 8(3):607-17. doi: 10.1038/mi.2014.93

145. Allen AC, Wilk MM, Misiak A, Borkner L, Murphy D, Mills KHG. Sustained Protective Immunity Against Bordetella Pertussis Nasal Colonization by Intranasal Immunization With a Vaccine-Adjuvant Combination That Induces IL-17-Secreting TRM Cells. Mucosal Immunol (2018) 11(6):176376. doi: 10.1038/s41385-018-0080-x

146. Auderset F, Ballester M, Mastelic-Gavillet B, Fontannaz P, Chabaud-Riou M, Reveneau N, et al. Reactivating Immunity Primed by Acellular Pertussis Vaccines in the Absence of Circulating Antibodies: Enhanced Bacterial Control by TLR9 Rather Than TLR4 Agonist-Including Formulation. Front Immunol (2019) 10:1520. doi: 10.3389/fimmu.2019.01520

147. Jahnmatz M, Richert L, Al-Tawil N, Storsaeter J, Colin C, Bauduin C, et al. Safety and Immunogenicity of the Live Attenuated Intranasal Pertussis Vaccine BPZE1: A Phase 1b, Double-Blind, Randomised, PlaceboControlled Dose-Escalation Study. Lancet Infect Dis (2020) 20(11):1290301. doi: 10.1016/S1473-3099(20)30274-7

148. Locht C. Live Pertussis Vaccines: Will They Protect Against Carriage and Spread of Pertussis? Clin Microbiol Infect (2016) 22(Suppl 5):S96-S102. doi: 10.1016/j.cmi.2016.05.029

149. Debrie AS, Mielcarek N, Lecher S, Roux X, Sirard JC, Locht C. Early Protection Against Pertussis Induced by Live Attenuated Bordetella Pertussis BPZE1 Depends on TLR4. J Immunol (2019) 203(12):3293-300. doi: 10.4049/jimmunol.1901102

150. de Graaf H, Ibrahim M, Hill AR, Gbesemete D, Vaughan AT, Gorringe A, et al. Controlled Human Infection With Bordetella Pertussis Induces Asymptomatic, Immunizing Colonization. Clin Infect Dis (2020) 71 (2):403-11. doi: 10.1093/cid/ciz840

151. Consortium P. PERISCOPE: Road Towards Effective Control of Pertussis. Lancet Infect Dis (2019) 19(5):e179-86. doi: 10.1016/S1473-3099(18)30646-7

152. Iwasaki A, Pillai PS. Innate Immunity to Influenza Virus Infection. Nat Rev Immunol (2014) 14(5):315-28. doi: 10.1038/nri3665

153. CDC. Types of Influenza Viruses: Centers for Disease Control and Prevention, National Center for Immunization and Respiratory Diseases (NCIRD) (November 18, 2019). Available at: https://www.cdc.gov/flu/about/viruses/ types.htm.

154. Manicassamy B, Manicassamy S, Belicha-Villanueva A, Pisanelli G, Pulendran B, Garcia-Sastre A. Analysis of In Vivo Dynamics of Influenza Virus Infection in Mice Using a GFP Reporter Virus. Proc Natl Acad Sci USA (2010) 107(25):11531-6. doi: 10.1073/pnas.0914994107

155. Pang IK, Iwasaki A. Control of Antiviral Immunity by Pattern Recognition and the Microbiome. Immunol Rev (2012) 245(1):209-26. doi: 10.1111/ j.1600-065X.2011.01073.X

156. Pichlmair A, Schulz O, Tan CP, Naslund TI, Liljestrom P, Weber F, et al. RIG-I-Mediated Antiviral Responses to Single-Stranded RNA Bearing 5'Phosphates. Science (2006) 314(5801):997-1001. doi: 10.1126/ science.1132998

157. Wisskirchen C, Ludersdorfer TH, Muller DA, Moritz E, Pavlovic J. The Cellular RNA Helicase UAP56 Is Required for Prevention of DoubleStranded RNA Formation During Influenza A Virus Infection. J Virol (2011) 85(17):8646-55. doi: 10.1128/JVI.02559-10

158. Schulz O, Diebold SS, Chen M, Naslund TI, Nolte MA, Alexopoulou L, et al. Toll-Like Receptor 3 Promotes Cross-Priming to Virus-Infected Cells. Nature (2005) 433(7028):887-92. doi: 10.1038/nature03326

159. Le Goffic R, Pothlichet J, Vitour D, Fujita T, Meurs E, Chignard M, et al. Cutting Edge: Influenza A Virus Activates TLR3-Dependent Inflammatory and RIG-I-Dependent Antiviral Responses in Human Lung Epithelial Cells. J Immunol (2007) 178(6):3368-72. doi: 10.4049/jimmunol.178.6.3368

160. Le Goffic R, Balloy V, Lagranderie M, Alexopoulou L, Escriou N, Flavell R, et al. Detrimental Contribution of the Toll-Like Receptor (TLR)3 to Influenza A Virus-Induced Acute Pneumonia. PloS Pathog (2006) 2(6):e53. doi: 10.1371/journal.ppat.0020053
161. Guillot L, Le Goffic R, Bloch S, Escriou N, Akira S, Chignard M, et al. Involvement of Toll-Like Receptor 3 in the Immune Response of Lung Epithelial Cells to Double-Stranded RNA and Influenza A Virus. J Biol Chem (2005) 280(7):5571-80. doi: 10.1074/jbc.M410592200

162. Heer AK, Shamshiev A, Donda A, Uematsu S, Akira S, Kopf M, et al. TLR Signaling Fine-Tunes Anti-Influenza B Cell Responses Without Regulating Effector T Cell Responses. J Immunol (2007) 178(4):2182-91. doi: 10.4049/ jimmunol.178.4.2182

163. Palladino G, Mozdzanowska K, Washko G, Gerhard W. Virus-Neutralizing Antibodies of Immunoglobulin G (IgG) But Not of IgM or IgA Isotypes can Cure Influenza Virus Pneumonia in SCID Mice. J Virol (1995) 69(4):207581. doi: 10.1128/JVI.69.4.2075-2081.1995

164. Wu H, Haist V, Baumgartner W, Schughart K. Sustained Viral Load and Late Death in Rag2-/- Mice After Influenza A Virus Infection. Virol J (2010) 7:172. doi: 10.1186/1743-422X-7-172

165. Clemens E, Angeletti D, Holbrook BC, Kanekiyo M, Jorgensen MJ, Graham BS, et al. Influenza-Infected Newborn and Adult Monkeys Exhibit a Strong Primary Antibody Response to Hemagglutinin Stem. JCI Insight (2020) 5(5). doi: 10.1172/jci.insight. 135449

166. Graham MB, Braciale TJ. Resistance to and Recovery From Lethal Influenza Virus Infection in B Lymphocyte-Deficient Mice. J Exp Med (1997) 186 (12):2063-8. doi: 10.1084/jem.186.12.2063

167. Lee BO, Rangel-Moreno J, Moyron-Quiroz JE, Hartson L, Makris M, Sprague F, et al. CD4 T Cell-Independent Antibody Response Promotes Resolution of Primary Influenza Infection and Helps to Prevent Reinfection. J Immunol (2005) 175(9):5827-38. doi: 10.4049/jimmunol.175.9.5827

168. Waffarn EE, Baumgarth N. Protective B Cell Responses to Flu-No Fluke! J Immunol (2011) 186(7):3823-9. doi: 10.4049/jimmunol.1002090

169. GeurtsvanKessel CH, Willart MA, van Rijt LS, Muskens F, Kool M, Baas C, et al. Clearance of Influenza Virus From the Lung Depends on Migratory Langerin + CD11b- But Not Plasmacytoid Dendritic Cells. J Exp Med (2008) 205(7):1621-34. doi: 10.1084/jem.20071365

170. Tamura S, Kurata T. Defense Mechanisms Against Influenza Virus Infection in the Respiratory Tract Mucosa. Jpn J Infect Dis (2004) 57(6):236-47.

171. Angeletti D, Gibbs JS, Angel M, Kosik I, Hickman HD, Frank GM, et al. Defining B Cell Immunodominance to Viruses. Nat Immunol (2017) 18 (4):456-63. doi: 10.1038/ni.3680

172. Hensley SE, Das SR, Bailey AL, Schmidt LM, Hickman HD, Jayaraman A, et al. Hemagglutinin Receptor Binding Avidity Drives Influenza A Virus Antigenic Drift. Science (2009) 326(5953):734-6. doi: 10.1126/ science. 1178258

173. Neu KE, Henry Dunand CJ, Wilson PC. Heads, Stalks and Everything Else: How can Antibodies Eradicate Influenza as a Human Disease? Curr Opin Immunol (2016) 42:48-55. doi: 10.1016/j.coi.2016.05.012

174. van de Sandt CE, Kreijtz JH, Rimmelzwaan GF. Evasion of Influenza A Viruses From Innate and Adaptive Immune Responses. Viruses (2012) 4 (9):1438-76. doi: 10.3390/v4091438

175. Kreijtz JH, Fouchier RA, Rimmelzwaan GF. Immune Responses to Influenza Virus Infection. Virus Res (2011) 162(1-2):19-30. doi: 10.1016/ j.virusres.2011.09.022

176. Treanor JJ, Tierney EL, Zebedee SL, Lamb RA, Murphy BR. Passively Transferred Monoclonal Antibody to the M2 Protein Inhibits Influenza A Virus Replication in Mice. J Virol (1990) 64(3):1375-7. doi: 10.1128/ JVI.64.3.1375-1377.1990

177. Carragher DM, Kaminski DA, Moquin A, Hartson L, Randall TD. A Novel Role for Non-Neutralizing Antibodies Against Nucleoprotein in Facilitating Resistance to Influenza Virus. J Immunol (2008) 181(6):4168-76. doi: 10.4049/jimmunol.181.6.4168

178. Jegaskanda S, Weinfurter JT, Friedrich TC, Kent SJ. Antibody-Dependent Cellular Cytotoxicity Is Associated With Control of Pandemic H1N1 Influenza Virus Infection of Macaques. J Virol (2013) 87(10):5512-22. doi: 10.1128/JVI.03030-12

179. Morimoto N, Takeishi K. Change in the Efficacy of Influenza Vaccination After Repeated Inoculation Under Antigenic Mismatch: A Systematic Review and Meta-Analysis. Vaccine (2018) 36(7):949-57. doi: 10.1016/ j.vaccine.2018.01.023

180. Brown DM, Lee S, Garcia-Hernandez Mde L, Swain SL. Multifunctional CD4 Cells Expressing Gamma Interferon and Perforin Mediate Protection 
Against Lethal Influenza Virus Infection. J Virol (2012) 86(12):6792-803. doi: 10.1128/JVI.07172-11

181. Brown DM, Dilzer AM, Meents DL, Swain SL. CD4 T Cell-Mediated Protection From Lethal Influenza: Perforin and Antibody-Mediated Mechanisms Give a One-Two Punch. J Immunol (2006) 177(5):2888-98. doi: 10.4049/jimmunol.177.5.2888

182. Baumgarth N, Kelso A. In Vivo Blockade of Gamma Interferon Affects the Influenza Virus-Induced Humoral and the Local Cellular Immune Response in Lung Tissue. J Virol (1996) 70(7):4411-8. doi: 10.1128/JVI.70.7.4411-4418.1996

183. Graham MB, Braciale VL, Braciale TJ. Influenza Virus-Specific CD4+ T Helper Type $2 \mathrm{~T}$ Lymphocytes do Not Promote Recovery From Experimental Virus Infection. J Exp Med (1994) 180(4):1273-82. doi: $10.1084 / \mathrm{jem} .180 .4 .1273$

184. Brown DM, Kamperschroer C, Dilzer AM, Roberts DM, Swain SL. IL-2 and Antigen Dose Differentially Regulate Perforin- and FasL-Mediated Cytolytic Activity in Antigen Specific CD4+ T Cells. Cell Immunol (2009) 257(1-2):6979. doi: 10.1016/j.cellimm.2009.03.002

185. Hua L, Yao S, Pham D, Jiang L, Wright J, Sawant D, et al. CytokineDependent Induction of CD4+ T Cells With Cytotoxic Potential During Influenza Virus Infection. J Virol (2013) 87(21):11884-93. doi: 10.1128/ JVI.01461-13

186. Betts RJ, Prabhu N, Ho AW, Lew FC, Hutchinson PE, Rotzschke O, et al. Influenza A Virus Infection Results in a Robust, Antigen-Responsive, and Widely Disseminated Foxp3+ Regulatory T Cell Response. J Virol (2012) 86 (5):2817-25. doi: 10.1128/JVI.05685-11

187. Arpaia N, Green JA, Moltedo B, Arvey A, Hemmers S, Yuan S, et al. A Distinct Function of Regulatory T Cells in Tissue Protection. Cell (2015) 162 (5):1078-89. doi: 10.1016/j.cell.2015.08.021

188. Leon B, Bradley JE, Lund FE, Randall TD, Ballesteros-Tato A. FoxP3+ Regulatory T Cells Promote Influenza-Specific Tfh Responses by Controlling IL-2 Availability. Nat Commun (2014) 5:3495. doi: 10.1038/ncomms4495

189. Belz GT, Xie W, Altman JD, Doherty PC. A Previously Unrecognized H-2D (B)-Restricted Peptide Prominent in the Primary Influenza A Virus-Specific CD8(+) T-Cell Response Is Much Less Apparent Following Secondary Challenge. J Virol (2000) 74(8):3486-93. doi: 10.1128/jvi.74.8.34863493.2000

190. Bender BS, Croghan T, Zhang L, Small PA Jr. Transgenic Mice Lacking Class I Major Histocompatibility Complex-Restricted T Cells Have Delayed Viral Clearance and Increased Mortality After Influenza Virus Challenge. J Exp Med (1992) 175(4):1143-5. doi: 10.1084/jem.175.4.1143

191. Brincks EL, Katewa A, Kucaba TA, Griffith TS, Legge KL. CD8 T Cells Utilize TRAIL to Control Influenza Virus Infection. J Immunol (2008) 181(7):491825. doi: 10.4049/jimmunol.181.7.4918

192. Krammer F, Smith GJD, Fouchier RAM, Peiris M, Kedzierska K, Doherty PC, et al. Influenza. Nat Rev Dis Primers (2018) 4(1):3. doi: 10.1038/s41572018-0002-y

193. Schmidt ME, Varga SM. The CD8 T Cell Response to Respiratory Virus Infections. Front Immunol (2018) 9:678. doi: 10.3389/fimmu.2018.00678

194. Kim CW, Yoo HJ, Park JH, Oh JE, Lee HK. Exogenous Interleukin-33 Contributes to Protective Immunity via Cytotoxic T-Cell Priming Against Mucosal Influenza Viral Infection. Viruses (2019) 11(9). doi: 10.3390/ v11090840

195. Sun J, Madan R, Karp CL, Braciale TJ. Effector T Cells Control Lung Inflammation During Acute Influenza Virus Infection by Producing IL-10. Nat Med (2009) 15(3):277-84. doi: 10.1038/nm.1929

196. Garcia-Sastre A. Induction and Evasion of Type I Interferon Responses by Influenza Viruses. Virus Res (2011) 162(1-2):12-8. doi: 10.1016/ j.virusres.2011.10.017

197. Chen YQ, Wohlbold TJ, Zheng NY, Huang M, Huang Y, Neu KE, et al. Influenza Infection in Humans Induces Broadly Cross-Reactive and Protective Neuraminidase-Reactive Antibodies. Cell (2018) 173(2):417-29 e10. doi: 10.1016/j.cell.2018.03.030

198. Ehrlich HJ, Muller M, Kollaritsch H, Pinl F, Schmitt B, Zeitlinger M, et al. Pre-Vaccination Immunity and Immune Responses to a Cell CultureDerived Whole-Virus H1N1 Vaccine Are Similar to a Seasonal Influenza Vaccine. Vaccine (2012) 30(30):4543-51. doi: 10.1016/j.vaccine.2012.03.061

199. Fritz R, Sabarth N, Kiermayr S, Hohenadl C, Howard MK, Ilk R, et al. A Vero Cell-Derived Whole-Virus H5N1 Vaccine Effectively Induces
Neuraminidase-Inhibiting Antibodies. J Infect Dis (2012) 205(1):28-34. doi: 10.1093/infdis/jir711

200. Krammer F. The Human Antibody Response to Influenza A Virus Infection and Vaccination. Nat Rev Immunol (2019) 19(6):383-97. doi: 10.1038/ s41577-019-0143-6

201. Oxford JS, Schild GC, Potter CW, Jennings R. The Specificity of the AntiHaemagglutinin Antibody Response Induced in Man by Inactivated Influenza Vaccines and by Natural Infection. J Hyg (Lond) (1979) 82 (1):51-61. doi: 10.1017/s0022172400025468

202. Fonville JM, Wilks SH, James SL, Fox A, Ventresca M, Aban M, et al. Antibody Landscapes After Influenza Virus Infection or Vaccination. Science (2014) 346(6212):996-1000. doi: 10.1126/science.1256427

203. Bodewes R, Kreijtz JH, Baas C, Geelhoed-Mieras MM, de Mutsert G, van Amerongen G, et al. Vaccination Against Human Influenza A/H3N2 Virus Prevents the Induction of Heterosubtypic Immunity Against Lethal Infection With Avian Influenza A/H5N1 Virus. PloS One (2009) 4(5):e5538. doi: 10.1371/journal.pone.0005538

204. Krammer F, Palese P. Advances in the Development of Influenza Virus Vaccines. Nat Rev Drug Discov (2015) 14(3):167-82. doi: 10.1038/nrd4529

205. Dunkle LM, Izikson R. Recombinant Hemagglutinin Influenza Vaccine Provides Broader Spectrum Protection. Expert Rev Vaccines (2016) 15 (8):957-66. doi: 10.1080/14760584.2016.1203261

206. Dunkle LM, Izikson R, Patriarca P, Goldenthal KL, Muse D, Callahan J, et al. Efficacy of Recombinant Influenza Vaccine in Adults 50 Years of Age or Older. N Engl J Med (2017) 376(25):2427-36. doi: 10.1056/NEJMoa1608862

207. Richards KA, Moritzky S, Shannon I, Fitzgerald T, Yang H, Branche A, et al. Recombinant HA-Based Vaccine Outperforms Split and Subunit Vaccines in Elicitation of Influenza-Specific CD4 T Cells and CD4 T Cell-Dependent Antibody Responses in Humans. NPJ Vaccines (2020) 5:77. doi: 10.1038/ s41541-020-00227-x

208. Zost SJ, Parkhouse K, Gumina ME, Kim K, Diaz Perez S, Wilson PC, et al. Contemporary H3N2 Influenza Viruses Have a Glycosylation Site That Alters Binding of Antibodies Elicited by Egg-Adapted Vaccine Strains. Proc Natl Acad Sci USA (2017) 114(47):12578-83. doi: 10.1073/pnas.1712377114

209. Su F, Patel GB, Hu S, Chen W. Induction of Mucosal Immunity Through Systemic Immunization: Phantom or Reality? Hum Vaccin Immunother (2016) 12(4):1070-9. doi: 10.1080/21645515.2015.1114195

210. Johnson PR Jr., Feldman S, Thompson JM, Mahoney JD, Wright PF. Comparison of Long-Term Systemic and Secretory Antibody Responses in Children Given Live, Attenuated, or Inactivated Influenza A Vaccine. J Med Virol (1985) 17(4):325-35. doi: 10.1002/jmv.1890170405

211. Belshe RB, Edwards KM, Vesikari T, Black SV, Walker RE, Hultquist M, et al. Live Attenuated Versus Inactivated Influenza Vaccine in Infants and Young Children. N Engl J Med (2007) 356(7):685-96. doi: 10.1056/NEJMoa065368

212. Isakova-Sivak I, Rudenko L. Safety, Immunogenicity and Infectivity of New Live Attenuated Influenza Vaccines. Expert Rev Vaccines (2015) 14 (10):1313-29. doi: 10.1586/14760584.2015.1075883

213. Hoft DF, Babusis E, Worku S, Spencer CT, Lottenbach K, Truscott SM, et al. Live and Inactivated Influenza Vaccines Induce Similar Humoral Responses, But Only Live Vaccines Induce Diverse T-Cell Responses in Young Children. J Infect Dis (2011) 204(6):845-53. doi: 10.1093/infdis/jir436

214. Hoft DF, Lottenbach KR, Blazevic A, Turan A, Blevins TP, Pacatte TP, et al. Comparisons of the Humoral and Cellular Immune Responses Induced by Live Attenuated Influenza Vaccine and Inactivated Influenza Vaccine in Adults. Clin Vaccine Immunol (2017) 24(1). doi: 10.1128/CVI.00414-16

215. Li Z, Zhao Y, Li Y, Chen X. Adjuvantation of Influenza Vaccines to Induce Cross-Protective Immunity. Vaccines (Basel) (2021) 9(2). doi: 10.3390/ vaccines 9020075

216. Ko EJ, Kang SM. Immunology and Efficacy of MF59-Adjuvanted Vaccines. Hum Vaccin Immunother (2018) 14(12):3041-5. doi: 10.1080/ 21645515.2018.1495301

217. Seubert A, Monaci E, Pizza M, O'Hagan DT, Wack A. The Adjuvants Aluminum Hydroxide and MF59 Induce Monocyte and Granulocyte Chemoattractants and Enhance Monocyte Differentiation Toward Dendritic Cells. J Immunol (2008) 180(8):5402-12. doi: 10.4049/jimmunol.180.8.5402

218. Leroux-Roels G. Prepandemic H5N1 Influenza Vaccine Adjuvanted With AS03: A Review of the Pre-Clinical and Clinical Data. Expert Opin Biol Ther (2009) 9(8):1057-71. doi: 10.1517/14712590903066695 
219. Carter NJ, Curran MP. Live Attenuated Influenza Vaccine (FluMist(R); Fluenz): A Review of Its Use in the Prevention of Seasonal Influenza in Children and Adults. Drugs (2011) 71(12):1591-622. doi: 10.2165/11206860000000000-00000

220. Zens KD, Chen JK, Farber DL. Vaccine-Generated Lung Tissue-Resident Memory T Cells Provide Heterosubtypic Protection to Influenza Infection. JCI Insight (2016) 1(10). doi: 10.1172/jci.insight.85832

221. Baxter R, Eaton A, Hansen J, Aukes L, Caspard H, Ambrose CS. Safety of Quadrivalent Live Attenuated Influenza Vaccine in Subjects Aged 2-49years. Vaccine (2017) 35(9):1254-8. doi: 10.1016/j.vaccine.2017.01.062

222. Blanco-Lobo P, Nogales A, Rodriguez L, Martinez-Sobrido L. Novel Approaches for The Development of Live Attenuated Influenza Vaccines. Viruses (2019) 11(2). doi: 10.3390/v11020190

223. Nguyen TH, McAuley JL, Kim Y, Zheng MZ, Gherardin NA, Godfrey DI, et al. Influenza, But Not SARS-CoV-2, Infection Induces a Rapid Interferon Response That Wanes With Age and Diminished Tissue-Resident Memory CD8(+) T Cells. Clin Transl Immunol (2021) 10(1):e1242. doi: 10.1002/cti2.1242

224. Schmidt A, Lapuente D. T Cell Immunity Against Influenza: The Long Way From Animal Models Towards a Real-Life Universal Flu Vaccine. Viruses (2021) 13(2). doi: 10.3390/v13020199

225. Corder BN, Bullard BL, Poland GA, Weaver EA. A Decade in Review: A Systematic Review of Universal Influenza Vaccines in Clinical Trials During the 2010 Decade. Viruses (2020) 12(10). doi: 10.3390/v12101186

226. Khurana S, Chearwae W, Castellino F, Manischewitz J, King LR, Honorkiewicz A, et al. Vaccines With MF59 Adjuvant Expand the Antibody Repertoire to Target Protective Sites of Pandemic Avian H5N1 Influenza Virus. Sci Transl Med (2010) 2(15):15ra5. doi: 10.1126/scitranslmed.3000624

227. Kim YH, Hong KJ, Kim H, Nam JH. Influenza Vaccines: Past, Present, and Future. Rev Med Virol (2021) e2243. doi: 10.1002/rmv.2243

228. Hung IF, Zhang AJ, To KK, Chan JF, Li P, Wong TL, et al. Topical Imiquimod Before Intradermal Trivalent Influenza Vaccine for Protection Against Heterologous Non-Vaccine and Antigenically Drifted Viruses: A Single-Centre, Double-Blind, Randomised, Controlled Phase 2b/3 Trial. Lancet Infect Dis (2016) 16(2):209-18. doi: 10.1016/S1473-3099(15)00354-0

229. Wei CJ, Boyington JC, McTamney PM, Kong WP, Pearce MB, Xu L, et al. Induction of Broadly Neutralizing H1N1 Influenza Antibodies by Vaccination. Science (2010) 329(5995):1060-4. doi: 10.1126/science.1192517

230. Scorza FB, Pardi N. New Kids on the Block: RNA-Based Influenza Virus Vaccines. Vaccines (Basel) (2018) 6(2). doi: 10.3390/vaccines6020020

231. Isakova-Sivak I, Stepanova E, Mezhenskaya D, Matyushenko V, Prokopenko P, Sychev I, et al. Influenza Vaccine: Progress in a Vaccine That Elicits a Broad Immune Response. Expert Rev Vaccines (2021) 20(9):1097-112. doi: 10.1080/14760584.2021.1964961

232. Jain S, Venkataraman A, Wechsler ME, Peppas NA. Messenger RNA-Based Vaccines: Past, Present, and Future Directions in the Context of the COVID-19 Pandemic. Adv Drug Deliv Rev (2021) 179:114000. doi: 10.1016/j.addr.2021.114000

233. Lee S, Ryu JH. Influenza Viruses: Innate Immunity and mRNA Vaccines. Front Immunol (2021) 12:710647. doi: 10.3389/fimmu.2021.710647

234. Choi A, Garcia-Sastre A, Schotsaert M. Host Immune Response-Inspired Development of the Influenza Vaccine. Ann Allergy Asthma Immunol (2020) 125(1):28-35. doi: 10.1016/j.anai.2020.04.008

235. Sautto GA, Kirchenbaum GA, Ross TM. Towards a Universal Influenza Vaccine: Different Approaches for One Goal. Virol J (2018) 15(1):17. doi: 10.1186/s12985-017-0918-y

236. Wei CJ, Crank MC, Shiver J, Graham BS, Mascola JR, Nabel GJ. NextGeneration Influenza Vaccines: Opportunities and Challenges. Nat Rev Drug Discov (2020) 19(4):239-52. doi: 10.1038/s41573-019-0056-x

237. Alexander-Miller MA. Challenges for the Newborn Following Influenza Virus Infection and Prospects for an Effective Vaccine. Front Immunol (2020) 11:568651. doi: 10.3389/fimmu.2020.568651

238. Pulendran B, Ahmed R. Immunological Mechanisms of Vaccination. Nat Immunol (2011) 12(6):509-17. doi: 10.1038/ni.2039

239. King A. Vaccines Beyond Antibodies: Spurred by Pandemic Research, Are TCell Vaccines Moving Closer to Reality? EMBO Rep (2021) 22(11):e54073. doi: 10.15252/embr.202154073

240. Koff WC, Burton DR, Johnson PR, Walker BD, King CR, Nabel GJ, et al. Accelerating Next-Generation Vaccine Development for Global Disease Prevention. Science (2013) 340(6136):1232910. doi: 10.1126/science.1232910
241. Dowling DJ, van Haren SD, Scheid A, Bergelson I, Kim D, Mancuso CJ, et al. TLR7/8 Adjuvant Overcomes Newborn Hyporesponsiveness to Pneumococcal Conjugate Vaccine at Birth. JCI Insight (2017) 2(6):e91020. doi: 10.1172 /jci.insight. 91020

242. Nanishi E, Borriello F, O’Meara TR, McGrath ME, Saito Y, Haupt RE, et al. An Aluminum Hydroxide:CpG Adjuvant Enhances Protection Elicited by a SARS-CoV-2 Receptor-Binding Domain Vaccine in Aged Mice. Sci Transl Med (2021). doi: 10.1126/scitranslmed.abj5305

243. Pardi N, Hogan MJ, Porter FW, Weissman D. mRNA Vaccines - a New Era in Vaccinology. Nat Rev Drug Discov (2018) 17(4):261-79. doi: 10.1038/ nrd.2017.243

244. van Riel D, de Wit E. Next-Generation Vaccine Platforms for COVID-19. Nat Mater (2020) 19(8):810-2. doi: 10.1038/s41563-020-0746-0

245. Hubbell JA, Thomas SN, Swartz MA. Materials Engineering for Immunomodulation. Nature (2009) 462(7272):449-60. doi: 10.1038/ nature 08604

246. Swartz MA, Hirosue S, Hubbell JA. Engineering Approaches to Immunotherapy. Sci Transl Med (2012) 4(148):148rv9. doi: 10.1126/scitranslmed.3003763

247. Brito LA, Malyala P, O’Hagan DT. Vaccine Adjuvant Formulations: A Pharmaceutical Perspective. Semin Immunol (2013) 25(2):130-45. doi: 10.1016/j.smim.2013.05.007

248. Bachmann MF, Jennings GT. Vaccine Delivery: A Matter of Size, Geometry, Kinetics and Molecular Patterns. Nat Rev Immunol (2010) 10(11):787-96. doi: $10.1038 /$ nri2868

249. Moyer TJ, Zmolek AC, Irvine DJ. Beyond Antigens and Adjuvants: Formulating Future Vaccines. J Clin Invest (2016) 126(3):799-808. doi: $10.1172 /$ JCI 81083

250. Holmgren J, Czerkinsky C. Mucosal Immunity and Vaccines. Nat Med (2005) 11(4 Suppl):S45-53. doi: 10.1038/nm1213

251. Kupper TS, Fuhlbrigge RC. Immune Surveillance in the Skin: Mechanisms and Clinical Consequences. Nat Rev Immunol (2004) 4(3):211-22. doi: $10.1038 /$ nri1310

252. Mitragotri S. Immunization Without Needles. Nat Rev Immunol (2005) 5 (12):905-16. doi: 10.1038/nri1728

253. Gostic KM, Bridge R, Brady S, Viboud C, Worobey M, Lloyd-Smith JO. Childhood Immune Imprinting to Influenza A Shapes Birth Year-Specific Risk During Seasonal H1N1 and H3N2 Epidemics. PloS Pathog (2019) 15 (12):e1008109. doi: 10.1371/journal.ppat.1008109

254. Vono M, Eberhardt CS, Mohr E, Auderset F, Christensen D, Schmolke M, et al. Overcoming the Neonatal Limitations of Inducing Germinal Centers Through Liposome-Based Adjuvants Including C-Type Lectin Agonists Trehalose Dibehenate or Curdlan. Front Immunol (2018) 9:381. doi: 10.3389/fimmu.2018.00381

255. Vogel K, Pierau M, Arra A, Lampe K, Schlueter D, Arens C, et al. Developmental Induction of Human T-Cell Responses Against Candida Albicans and Aspergillus Fumigatus. Sci Rep (2018) 8(1):16904. doi: 10.1038/ s41598-018-35161-5

256. Han Q, Bradley T, Williams WB, Cain DW, Montefiori DC, Saunders KO, et al. Neonatal Rhesus Macaques Have Distinct Immune Cell Transcriptional Profiles Following HIV Envelope Immunization. Cell Rep (2020) 30(5):155369.e6. doi: 10.1016/j.celrep.2019.12.091

257. Sanchez-Schmitz G, Stevens CR, Bettencourt IA, Flynn PJ, Schmitz-Abe K, Metser G, et al. Microphysiologic Human Tissue Constructs Reproduce Autologous Age-Specific BCG and HBV Primary Immunization. Vitro Front Immunol (2018) 9:2634. doi: 10.3389/fimmu.2018.02634

258. Goodridge HS, Ahmed SS, Curtis N, Kollmann TR, Levy O, Netea MG, et al. Harnessing the Beneficial Heterologous Effects of Vaccination. Nat Rev Immunol (2016) 16(6):392-400. doi: 10.1038/nri.2016.43

259. Sanchez-Ramon S, Conejero L, Netea MG, Sancho D, Palomares O, Subiza JL. Trained Immunity-Based Vaccines: A New Paradigm for the Development of Broad-Spectrum Anti-Infectious Formulations. Front Immunol (2018) 9:2936. doi: 10.3389/fimmu.2018.02936

260. Netea MG, Joosten LAB. Trained Immunity and Local Innate Immune Memory in the Lung. Cell (2018) 175(6):1463-5. doi: 10.1016/j.cell.2018.11.007

261. Jensen K, Dela Pena-Ponce MG, Piatak M Jr., Shoemaker R, Oswald K, Jacobs WR Jr, et al. Balancing Trained Immunity With Persistent Immune Activation and the Risk of Simian Immunodeficiency Virus Infection in Infant Macaques Vaccinated With Attenuated Mycobacterium Tuberculosis 
or Mycobacterium Bovis BCG Vaccine. Clin Vaccine Immunol CVI (2017) 24 (1). doi: $10.1128 /$ cvi.00360-16

262. Guevara-Hoyer K, Saz-Leal P, Diez-Rivero CM, Ochoa-Grullón J, Fernández-Arquero M, Pérez de Diego R, et al. Trained Immunity BasedVaccines as a Prophylactic Strategy in Common Variable Immunodeficiency. A Proof of Concept Study. Biomedicines (2020) 8(7). doi: 10.3390/ biomedicines 8070203

263. O'Neill LAJ, Netea MG. BCG-Induced Trained Immunity: Can It Offer Protection Against COVID-19? Nat Rev Immunol (2020) 20(6):335-7. doi: 10.1038/s41577-020-0337-y

264. Mulder WJM, Ochando J, Joosten LAB, Fayad ZA, Netea MG. Therapeutic Targeting of Trained Immunity. Nat Rev Drug Discov (2019) 18(7):553-66. doi: 10.1038/s41573-019-0025-4

265. Nicoli F, Appay V. Immunological Considerations Regarding Parental Concerns on Pediatric Immunizations. Vaccine (2017) 35(23):3012-9. doi: $10.1016 /$ j.vaccine.2017.04.030

266. Mueller AL, McNamara MS, Sinclair DA. Why Does COVID-19 Disproportionately Affect Older People? Aging (Albany NY) (2020) 12 (10):9959-81. doi: 10.18632/aging.103344

267. Barbet G, Sander LE, Geswell M, Leonardi I, Cerutti A, Iliev I, et al. Sensing Microbial Viability Through Bacterial RNA Augments T Follicular Helper Cell and Antibody Responses. Immunity (2018) 48(3):584-98 e5. doi: 10.1016/j.immuni.2018.02.015

268. Kelvin AA, Zambon M. Influenza Imprinting in Childhood and the Influence on Vaccine Response Later in Life. Euro Surveill (2019) 24(48). doi: 10.2807/1560-7917.ES.2019.24.48.1900720
269. Cirovic B, de Bree LCJ, Groh L, Blok BA, Chan J, van der Velden W, et al. BCG Vaccination in Humans Elicits Trained Immunity via the Hematopoietic Progenitor Compartment. Cell Host Microbe (2020) 28 (2):322-34.e5. doi: 10.1016/j.chom.2020.05.014

Conflict of Interest: DD is a named inventor on granted patents and patent applications related to vaccine adjuvants and vaccine formulation design. DS, BB and EN are named inventor on multiple patent applications focused on the design of the adjuvanted vaccine formulation.

The remaining authors declare that the research was conducted in the absence of any commercial or financial relationships that could be construed as a potential conflict of interest.

Publisher's Note: All claims expressed in this article are solely those of the authors and do not necessarily represent those of their affiliated organizations, or those of the publisher, the editors and the reviewers. Any product that may be evaluated in this article, or claim that may be made by its manufacturer, is not guaranteed or endorsed by the publisher.

Copyright $\odot 2022$ Barman, Soni, Brook, Nanishi and Dowling. This is an open-access article distributed under the terms of the Creative Commons Attribution License (CC BY). The use, distribution or reproduction in other forums is permitted, provided the original author(s) and the copyright owner(s) are credited and that the original publication in this journal is cited, in accordance with accepted academic practice. No use, distribution or reproduction is permitted which does not comply with these terms. 